\title{
Vulnerability curves vs. vulnerability indicators: application of an indicator-based methodology for debris-flow hazards
}

\author{
Maria Papathoma-Köhle \\ Institute of Mountain Risk Egineering, University of Natural Resources and Life Sciences, 1190 Vienna, Austria \\ Correspondence to: Maria Papathoma-Köhle (maria.papathoma-koehle@boku.ac.at)
}

Received: 7 March 2016 - Published in Nat. Hazards Earth Syst. Sci. Discuss.: 15 March 2016

Revised: 2 June 2016 - Accepted: 1 July 2016 - Published: 3 August 2016

\begin{abstract}
The assessment of the physical vulnerability of elements at risk as part of the risk analysis is an essential aspect for the development of strategies and structural measures for risk reduction. Understanding, analysing and, if possible, quantifying physical vulnerability is a prerequisite for designing strategies and adopting tools for its reduction. The most common methods for assessing physical vulnerability are vulnerability matrices, vulnerability curves and vulnerability indicators; however, in most of the cases, these methods are used in a conflicting way rather than in combination. The article focuses on two of these methods: vulnerability curves and vulnerability indicators. Vulnerability curves express physical vulnerability as a function of the intensity of the process and the degree of loss, considering, in individual cases only, some structural characteristics of the affected buildings. However, a considerable amount of studies argue that vulnerability assessment should focus on the identification of these variables that influence the vulnerability of an element at risk (vulnerability indicators). In this study, an indicator-based methodology (IBM) for mountain hazards including debris flow (Kappes et al., 2012) is applied to a case study for debris flows in South Tyrol, where in the past a vulnerability curve has been developed. The relatively "new" indicator-based method is being scrutinised and recommendations for its improvement are outlined. The comparison of the two methodological approaches and their results is challenging since both methodological approaches deal with vulnerability in a different way. However, it is still possible to highlight their weaknesses and strengths, show clearly that both methodologies are necessary for the assessment of physical vulnerability and provide a preliminary "holistic methodological framework" for physical vulnera-
\end{abstract}

bility assessment showing how the two approaches may be used in combination in the future.

\section{Introduction}

Climate and environmental change are expected to alter the patterns of risk in mountain areas. On one hand, the frequency, magnitude and spatial extend of natural hazards is expected to change; on the other hand, extensive development and changes in land use and land cover will certainly alter the spatial pattern of the vulnerability of the elements at risk (Fuchs et al., 2013; Mazzorana et al., 2012). Especially in the Alps, the influence of climate change on geomorphological hazards as well as their monitoring and modelling is a major issue (Keiler et al., 2010). It is clear that although predicting, monitoring and assessing the hazardous process is essential, the analysis of the vulnerability of the elements at risk may be the key to risk reduction. To address vulnerability in a holistic way, all its dimensions (social, economic, physical, environmental, institutional) should be addressed and analysed (Fuchs et al., 2011; Karagiorgos et al., 2016). However, herein the focus is solely on the physical vulnerability of buildings. Physical vulnerability is often considered to be the degree of loss following a disastrous event. Nevertheless, the characteristics of the elements at risk that constitute them susceptible to harm are often overlooked and have to be further investigated. The most common method for assessing vulnerability is the development of vulnerability curves that often ignore the characteristics of the buildings, especially when the type of hazard under investigation affects a limited amount of buildings (e.g. debris flow), focusing mainly on the intensity of the process and the corresponding loss. At 
this point, the difference between fragility curves and vulnerability curves has to be highlighted. Fragility curves express the probability that a building will be damaged as a function of the intensity of the process, whereas vulnerability curves relate the intensity with the corresponding degree of loss. HAZUS, for example, defines five damage states for buildings subject to earthquake hazard (none, slight, moderate, extensive and complete) and develops fragility curves for different building types (HAZUS, 2006). HAZUS fragility curves present the probability for these five damage states to occur under different peak ground acceleration (PGA) values (HAZUS, 2006). Nevertheless, vulnerability curves for different types of buildings may also be found in the literature for earthquake, wind and flood hazards. In the present study an indicator-based methodology (IBM) is applied in Martell (South Tyrol, Italy) for debris flows. The same case study area has been used in the past for the development of a vulnerability curve based on damage data from a debris flow event in 1987 (Papathoma-Köhle et al., 2012). By comparing the results of the two methods, the advantages and disadvantages of the IBM can be highlighted and recommendations for its further development and improvement can be outlined. Last but not least, a preliminary framework proposing the combination of these methods may be proposed.

\section{Physical vulnerability assessment: the PTVA method and the use of indicators}

Due to the multi-dimensional nature of vulnerability a long list of definitions can be found in the literature varying from general ones to more dimension-specific ones. As far as the physical vulnerability is concerned, the definition of UNDRO (1984) ("vulnerability is the degree of loss to a given element, or set of elements, within the area affected by a hazard. It is expressed on a scale of 0 (no loss) to 1 (total loss)") is in conflict with other, more general, definitions presenting vulnerability as susceptibility to harm or the result of a combination of characteristics of the elements at risk. For example, according to (UNISDR, 2009) vulnerability is defined as "the characteristics and circumstances of a community, system or asset that makes it susceptible to the damaging effects of a hazard", often used by social scientists to describe the social dimension of vulnerability. The first definition is based on the ex post outcome of a specific event, whereas, the second is based on the ex ante condition of the elements at risk without considering the intensity or the characteristics of the hazardous process. From these two definitions various approaches for vulnerability assessment derive that require different datasets leading to diverse results. It is, therefore, clear that the lack of common definition for vulnerability results to the absence of a universal methodology for its assessment.

\subsection{Methods for assessing physical vulnerability}

The variety of methodologies and concepts regarding vulnerability in general has been highlighted and demonstrated in several publications (e.g. Fuchs et al., 2012; PapathomaKöhle et al., 2011). The most common approaches for assessing vulnerability in general are vulnerability matrices, vulnerability curves and indicator-based approaches (Kappes et al., 2012). Vulnerability matrices provide only qualitative information on vulnerability based on descriptions of damage patterns. Regarding physical vulnerability, vulnerability curves are the most common method for assessing physical vulnerability as far as mountain hazards are concerned (Papathoma-Köhle et al., 2011). The vulnerability of buildings to natural hazards is determined by a number of attributes such as building material, size and condition (Fuchs et al., 2007; Tarbotton et al., 2015) as well as the availability of local structural protection (Holub et al., 2012). However, these attributes and their combination vary from building to building. This makes data collection a time-consuming process which requires a detailed building-to-building investigation. Consequently, decision makers and practitioners prefer to use data from past events to develop empirical vulnerability models such as vulnerability curves (Tarbotton et al., 2015). Another reason that makes vulnerability curves so popular among practitioners is that they connect directly the intensity of a process with the corresponding degree of loss, providing concrete quantitative results and translating potential events into monetary damage (Mazzorana et al., 2009). Tarbotton et al. (2015) suggest that the accuracy and reliability of the results of empirical vulnerability curves depend on a series of factors including: the survey method for the data collection, the accuracy of the data regarding the building damage as well as the building characteristics and the statistical method used for the analysis of the data. In more detail, according to the same authors, the survey method may be remote (e.g. the building damage and type may be identified by the use of ortho-photos) or on site (field survey). The remote survey methods are faster and cheaper but also inaccurate, whereas the field survey is accurate but time-consuming and expensive. Moreover, for the development of the vulnerability curves the intensity has to be expressed in a measurable way (e.g. height of deposit or impact pressure). The choice of the parameter of the intensity that will be used for its expression influences the result (Tarbotton et al., 2015). Additionally, Tarbotton et al. (2015) point out that the uncertainty of the results is increasing with the use of interpolation in order to identify the intensity of a process on individual buildings. Last but not least, the number of buildings used for the development of a vulnerability curve also influences the accuracy and validity of the results. In case of earthquakes or floods the assessment of the intensity per building is easier and the number of affected buildings is large. Intensity per building is often the product of interpolation and the structural characteristics of the buildings are ignored. In these cases, how- 
ever, it is relatively uncomplicated to develop reliable vulnerability curves due to sufficient data availability. For other hazard types, such as rock falls, this is not the case since a single event affects only a limited amount of elements at risk and the assessment of the process intensity on each of them is a challenging process. Moreover, vulnerability curves do not consider the individual features of the buildings or characteristics related to their location and surroundings (Fuchs, 2009). Although they provide concrete information regarding the loss, they do not provide information concerning the drivers of vulnerability or potential ways of reducing it.

As far as debris flow is concerned, the first approaches for physical vulnerability assessment were qualitative (Fell and Hartford, 1997; Liu and Lei, 2003; Romang, 2004), including in some cases vulnerability matrices (Leone et al., 1995, 1996; Sterlacchini et al., 2007; Zanchetta et al., 2004) showing a descriptive relationship between the damage and intensity of the flow. However, recently the number of vulnerability curves for debris flows has considerably increased and several studies may be found in the literature (Fuchs et al., 2007; Papathoma-Köhle et al., 2012; Quan Luna et al., 2011; Totschnig and Fuchs, 2013; Totschnig et al., 2011). Each vulnerability curve has been developed for a specific area, is based on a particular catastrophic event and expresses the intensity of the process in various ways. For example, there are curves based on data for a small (e.g. 13 buildings in Fuchs et al., 2007) or a larger number of buildings (1560 buildings in Lo et al., 2012). In some cases, due to lack of empirical data, information on the process had to be derived through modelling (Quan Luna et al., 2011; Rheinberger et al., 2013) that expressed the flow not only as debris height but also as velocity, viscosity or impact pressure. As far as the degree of loss is concerned, relevant information could be provided in some cases by the authorities. Nevertheless, where damage data were not available, damage costs were assessed based on photographic documentation (e.g. Papathoma-Köhle et al., 2012). Last but not least, it is worth mentioning that a number of studies focus on laboratory experiments in order to determine the interaction between the flow and the structural components of the buildings (Gems et al., 2016; Zhang et al., 2016).

In contrast, shortage of empirical data often leads to the development of vulnerability indices based on the selection, weighting and aggregation of vulnerability indicators. IBMs have been used mainly for other vulnerability dimensions, such as social or economic vulnerability. However, recently a considerable number of studies are available that make use of vulnerability indicators for the assessment of other vulnerability dimensions (e.g. physical). Vulnerability indicators, according to Birkmann (2006), are "variables which are operation representations of a characteristic quality of the system able to provide information regarding the susceptibility, coping capacity and resilience of a system to an impact of an albeit ill-defined event linked to a hazard of a natural origin". The importance of developing and using indicators has been also stressed in Hyogo Framework, by identifying, as a key activity, the development of "systems of indicators of disaster risk and vulnerability at national and sub-national scales that will enable decision makers to assess the impact of disasters on social, economic and environmental conditions and disseminate the results to decision makers, the public and populations at risk" (UN, 2007). However, using indicators to assess vulnerability (any dimension of it) may be problematic due to a number of reasons (Barnett et al., 2008). In more detail, Barnett et al. (2008) suggest that the use of vulnerability indicators and indices for national scale is less meaningful, whereas for larger scale it might lead to policy relevant results; however, it still bears many uncertainties. The same authors also stress that challenges are mainly related to the selection of indicators, their standardisation, the availability of required data, their weighting and the method of aggregation for the development of a vulnerability index, concluding that empirical investigation (e.g. vulnerability curves) may lead to better results. Nevertheless, vulnerability indicators are very often used for the assessment of social vulnerability as, for example, in the Social Vulnerability Index of Cutter et al. (2003). Regarding physical vulnerability, although vulnerability curves are more popular than vulnerability indicators, studies using indicators for assessing physical vulnerability are on the rise. Some of these studies focus only on the development of inventories of elements at risk and their characteristics (Papathoma-Köhle et al., 2007) or they make an additional step towards exposure assessment (Fuchs et al., 2015). Barroca et al. (2006) developed a vulnerability analysis tool for floods based on a system of indicators describing the elements at risks, their spatial relation, the prevention, emergency and reconstruction systems. Barroca et al. (2006) suggest that the vulnerability assessment tool is simple and flexible and can be used by different users without requiring expert knowledge for its use. Moreover, Müller et al. (2011) assessed urban vulnerability towards flood using indicators for physical and social vulnerability. Concerning physical vulnerability, four indicators were selected (construction material, building position, proportion of green spaces and local structural protection) and ranked based on expert judgement. Most of the IBMs found in the literature are applied at local scale. The study of Balica et al. (2009) is noteworthy because the selected indicators used to develop indices for flood vulnerability are available for three scales (river basin, sub-catchment and urban area). Balica et al. (2009) suggest that the IBM is powerful because it supports decision makers in prioritisation underpinning transparency. Apart from floods, physical vulnerability has been investigated with means of indicators also for other hazard types such as landslides. Silva and Pereira (2014) assess physical vulnerability of buildings to landslides based on the building resistance and the landslide magnitude. The building's resistance is determined by a number of indicators including construction technique and material, number of floors, floor and roof structure and conservation status. 
Last but not least, Kappes et al. (2012) developed an IBM for multi-hazard in mountain areas which is presented in detail and applied in the present study. In general, in most of the studies, indicators are weighted empirically and no validation of their selection and weighting has been implemented using the damage pattern and loss from a real event.

\subsection{The PTVA method and its evolution}

One of the first attempts to use indicators for the assessment of physical vulnerability was made by Papathoma and Dominey-Howes (2003) and Papathoma et al. (2003). Specifically, they developed a methodology for assessing the physical vulnerability of buildings to tsunami at coastal areas in Greece using indicators. The main concept of the Papathoma Tsunami Vulnerability Assessment Model (PTVA) was the combination of an inundation scenario with "attributes relating to the design, condition and surroundings of the building" (Tarbotton et al., 2012). The methodology was based on the fact that two buildings located exactly at the same place despite experiencing the same process intensity do not always suffer the same loss. The reason for this is the variety of building characteristics concerning the building itself and its surroundings. A number of buildings characteristics related to the damage pattern following a tsunami event were selected (indicators) and a GIS database with the buildings and their attributes was created. The indicators were weighted using expert judgement and a vulnerability index was given to each building. The result was a series of maps for a number of coastal segments in Greece showing the spatial pattern of the relative physical vulnerability of the buildings. In this way, authorities and emergency services could focus their limited resources on specific buildings rather the whole potentially inundated area. The method was later validated (Dominey-Howes and Papathoma, 2007) using data from Maldives following the 2004 Indian Ocean tsunami. The validation showed that the selected vulnerability indicators correlate well with the severity of the damage; however, recommendations for improvement led to an improved version of the method: PTVA-2. PTVA-2 was used in the USA (Dominey-Howes et al., 2010) for the estimation of the probable maximum loss from a Cascadia tsunami in Oregon (USA). The main difference to PTVA-1 was the inclusion of the water depth above ground as an attribute in the calculation of the overall vulnerability. In this way, the method became more intensity dependant than before. PTVA-3 was developed by Dall'Osso et al. (2009a) and was tested in Australia (Dall'Osso et al., 2009b) and in Italy (Dall'Osso et al., 2010). PTVA-3 made a step towards and more reliable weighting of the vulnerability indicators by using analytical hierarchy process (AHP) rather than expert judgement to weight the attributes.

The first attempt to use vulnerability indicators for mountain hazards was made by Papathoma-Köhle et al. (2007) with the development of an elements at risk database contain- ing indicators regarding the physical vulnerability of buildings to landslides. However, due to the lack of data regarding the hazardous process itself and the limited availability of data regarding the building characteristics the study constitutes only a good basis for further research. The next attempt was made by Kappes et al. (2012), who introduced a methodology for vulnerability assessment using vulnerability indicators, e.g. characteristics of the building that are responsible for its susceptibility to damage and loss due to mountain hazards, based on the PTVA model. The methodology is presented in the following chapter. It is clear that as far as mountain hazards are concerned, there is definitely a need to improve and modify indicator-based approaches in order to be used for vulnerability assessment and as basis for risk reduction strategies.

The two methodological concepts have been always used separately rather than in combination from scientists and practitioners. A first effort to combine them has been made by Papathoma-Köhle et al. (2015). Papathoma-Köhle et al. (2015) developed a tool which uses the vulnerability curve presented in the following chapters as a core to implement three functions: updating and improvement of the curve with data from new events, damage and loss assessment for future events and damage documentation of new events. However, the tool has the possibility to include information regarding building characteristics. This provides the opportunity to investigate the correlation of damage patterns and the building characteristics in the future.

\section{The indicator-based methodology: a PTVA for debris flow}

The concept of the IBM for mountain hazards (debris flows, landslides and floods) is based on the assignment of weights to a number of building characteristics resulting to a relative vulnerability index (RVI) per building (Fig. 1). The RVI is calculated per building by using the following Eq. (1):

$\mathrm{RVI}=\sum_{1}^{m} w_{m} \cdot I_{m} s_{n}$,

where $w$ represents the $m$ different weights, $I$ the $m$ indicators and $s$ the $n$ scores of the indicators as shown in Fig. 1 . A selection of vulnerability indicators of buildings for debris flow events and the weighting according to different users are shown in Fig. 2. In more detail, the vulnerability indicators are related to building characteristics (material, condition, number of floors, building surroundings) and location (row towards torrent and row towards the slope). The indicators are weighted and aggregated according to Eq. (1) to a RVI which is attributed to each building.

However, the weighting is not static since the needs of the end users may vary. Therefore, each user of the method should be able to set their own priorities and change the weighting accordingly. For example, emergency services 


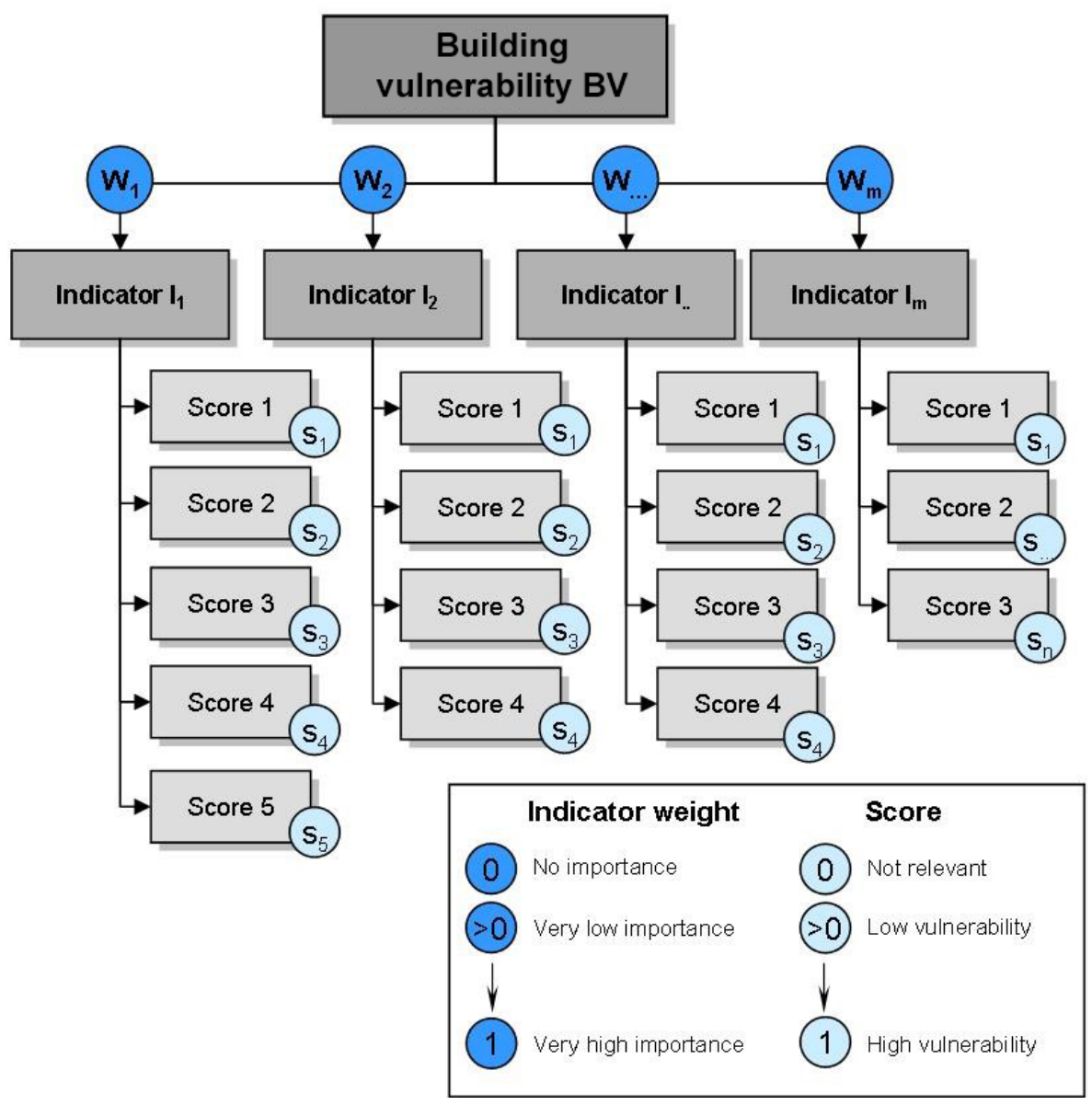

Figure 1. The concept of the IBM (Kappes et al., 2012).

need to know the physical vulnerability of the buildings in order to locate concentrated number of casualties and potential victims following an event. Therefore, one-floor buildings not offering vertical evacuation opportunities are of greater importance. "Vertical evacuation" refers often to any action aiming at moving people to a higher area (higher ground, upper floors of multi-storey building or a vertical shelter) (Velotti et al., 2013) and is growing in importance in the Netherlands as an emergency management option for floods (Velotti et al., 2013), whereas in Japan it is already used for tsunamis (Scheer et al., 2011). However, if the aim of the study is the development of vulnerability reduction efforts during the preparedness phase, building material and condition or the existence of building surroundings are of the highest importance. In this way, several RVIs may be calculated for each building by varying scores and weights: for exam-

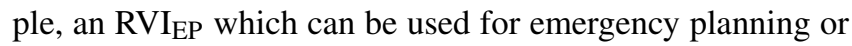
an $\mathrm{RVI}_{\mathrm{VR}}$ which can be used as a base for vulnerability reduction strategies (e.g. reinforcement of buildings).

Kappes et al. (2012) suggest that the main advantage of the method is the flexibility in weighting, although flexibility in this case increases subjectivity, which consequently increases the level of uncertainty. Moreover, they consider the fact that the method is not hazard-intensity specific to be an advantage, because the assessment may be carried out in absence of information regarding the process characteristics. In this case, although the focus is on physical vulnerability, vulnerability is considered to be an "inherent property of a system arising from its internal characteristics" as Adger et al. (2004) suggest. However, Adger et al. (2004) pointed out that this definition is appropriate only for "social vulnerability". Nevertheless, the approach of Kappes et al. (2012) is based on a "relative" vulnerability index which more or less highlights the buildings that are more vulnerable than the others. Kappes et al. (2012), based on the limitations of the method, outline the necessary actions that have to be taken in the future in order to improve the method. They recommend that damages of events have to be recorded in a more detailed way in order to comprehend the role of each indicator and their importance in determining the vulnerability of the building. Since the method requires a large amount of detailed data, alternative data collection methods may be introduced, e.g. questionnaires or remote sensing. Additional data, such data regarding open spaces, the accu- 


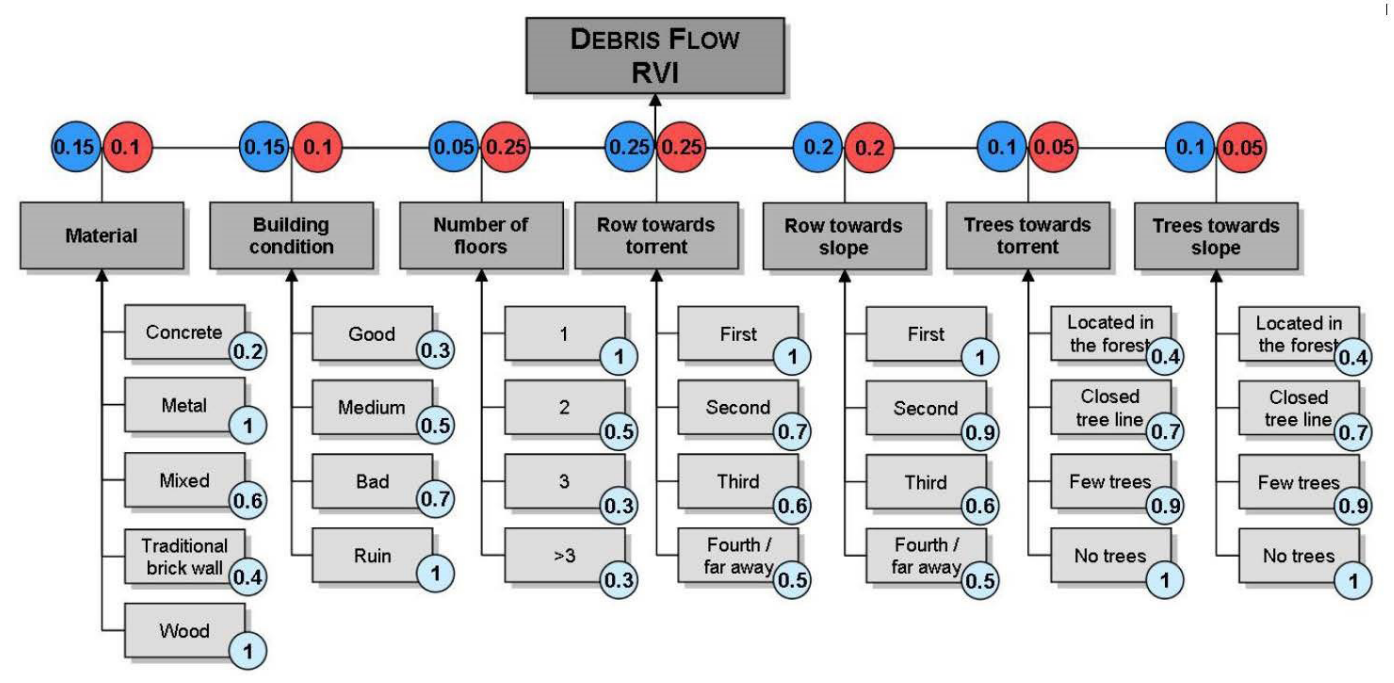

LEGEND

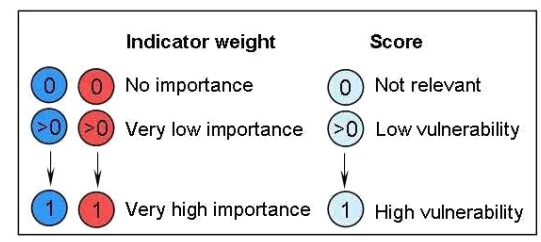

Objective: Vulnerability reduction / reinforcement Possible users: House owners, insurance, local authorities

Objective: Evacuation \& rescue

Possible users: Fire brigade, army, ambulance,

volunteers and other emergency services

Figure 2. The IBM adapted for debris flow. The vulnerability indicators are demonstrated together with the weight index, which varies according to the objective of the vulnerability assessment and the end users (Kappes et al., 2012).

mulation of movable objects or even additional elements at risk, such as agricultural spaces and industry, will make the method more integrated. Furthermore, the database could be enriched with socioeconomic data at building level. Last but not least, Kappes et al. (2012) suggest that an interesting development of the method would be the validation of the indicators weighting based on damage records of past events.

The weighting of the indicators has been done without carrying out a sensitivity analysis. A sensitivity analysis would be an important next step following the development of the IBM methodology of Kappes et al. (2012). A sensitivity analysis would show the different outcomes of the method by changing each time the assumptions - for example, the weighting of the indicators.

\section{The case study area}

The IBM has to be tested in an area that has not only a long record of debris flow events but also detailed documented damages on buildings. Damage documentation may additionally reveal information regarding the intensity of the event itself as well as the damage pattern on the built environment. For this reason, the methodology will be validated in Martell (South Tyrol, Italy). Communities in South Tyrol (Italy) often suffered material damages due to geomor- phological hazards such as landslides, flash floods and debris flows.

The municipality of Martell is located in the tributary valley of Vinschgau in South Tyrol, Italy. The valley of Martell is $27 \mathrm{~km}$ long with a ranging altitude from 950 to $3700 \mathrm{~m}$ (Martell, 2013). The settlements are located at the bottom of the valley which is mainly used for agriculture. Most of the built-up areas, such as Meiern, Gand, Ennewasser, and Burgaun are situated in the north part of the valley. Martell has a long record of water-related natural hazard events such as glacial lake outburst, floods, debris flows and avalanches. The loose material (debris) that was left behind by glaciers during the Holocene retreat has often been transported downstream by debris flows in the past, causing considerable material damage to the settlements of the valley. Additionally, a reservoir dam was constructed in 1956, which served mainly as an electrical power source and protected the village from unexpected excessive flooding.

On 24 August 1987, following some days of continuous and heavy precipitation, the river Plima transported a considerably higher amount of water than usual. Debris flows were initiated in tributary streams along the valley. In the evening, the inhabitants were successfully evacuated, as the water level continued to rise. A couple of hours after the evacuation, a large debris flow went through the valley, causing devastation. The specific debris flow event cannot be con- 
sidered as entirely natural, as it was directly connected to the mismanagement of the reservoir dam which failed to regulate the water flow into the valley (Pfitscher, 1996). The actual outflow has been estimated to be 3 times the usual discharge (300 to $350 \mathrm{~m}^{3} \mathrm{~s}^{-1}$ ). The debris flow reached the village of Gand, overflowed the river bed and found its way through the settlements. Not only were buildings destroyed, but significant damages were also recorded in agricultural areas, infrastructure and the industrial zone in Vinschgau (Pfitscher, 1996). Fortunately, due to the early warning and evacuation no casualties were recorded. Although the total damage summed up to ITL 45 to 50 billion (approximately EUR 23.2 to 25.8 million), private households suffered damages of slightly less than EUR 8 million.

As far as the infrastructure, local light industry, forestry, agriculture, tourism and emergency response are concerned, damages up to EUR 4 million were recorded. Furthermore, EUR 5.6 million had to be spent for the recovery of the regional road and the telecommunications network as well as for torrent control measures. At the time, only the direct costs of the event were assessed (Pfitscher, 1996). The event was documented mainly through photographic material (Fig. 4) that enabled later assessment of the intensity of the process as well as the damage pattern on individual buildings.

\section{The development of a vulnerability curve for the study area}

Following an intensive workshop with stakeholders from South Tyrol a methodology for developing a vulnerability curve for the area was created based on the needs of the stakeholders, their experience and the available data. The pilot study included the making of a vulnerability curve based on empirical damage data of buildings in Martell, South Tyrol, Italy, that were damaged during the 1987 debris flow event (Fig. 5). Following the event, the buildings, as well as parts of the affected villages, were photographed. These photographs give a very good overview of the damage pattern; however, information regarding the costs of the damages per building, or detailed descriptions of the damage, were not available. In more detail, photographic documentation of 51 buildings out of the 69 buildings that were damaged or completely destroyed during the event was used (Pfitscher, 1996), because only for this number of buildings was adequate photographic documentation available. Based on these photos, the height of the debris deposits per building could be estimated and the monetary damage was calculated. For example, in case the damage is limited to the exterior of the building, the works will include only restoration of the external walls. In case the debris has entered the building through openings or wall breaks, there will be additional renovation works such as removal of debris and restoration of interior walls and floor (Papathoma-Köhle et al., 2012). The extent of the damage per building was translated in monetary loss based on stan- dard prices for renovation works (Kaswalder, 2009). By comparing the value of a building in terms of reconstruction costs to the monetary damage caused by the event the degree of loss per building could be also assessed. Every building used in the analysis was represented as a point in the $x y$ axis system shown in Fig. 5. A Weibull function was fitted to the data points as this curve was the one that fulfilled the defined criteria (the curve has to go through 0 and not over degree of loss 1 ) and had the best $R^{2}$ (coefficient of determination).

The vulnerability curve clearly shows that the higher the intensity of the process the greater the damage that an element at risk suffers. The curve indicates that when the intensity exceeds $1.5 \mathrm{~m}$, the degree of loss increases considerably. This may be explained by the fact that debris flow of this height may easily enter the building from windows and doors and cause additional damage in the interior. However, at this point it is important to emphasise that only the structural damage was considered in the calculation of the monetary loss and not the content of the buildings. In more detail, the costs of the structural damage included cleaning up of the interior, repairing the exterior and interior walls, removing and replacing doors and windows, and testing and reinstalling electric, heating and sewage systems where necessary.

Finally, Papathoma-Köhle et al. (2012) computed a validation curve (blue curve in Fig. 3) using real compensation data for only part of the buildings provided by the Department of Domestic Construction of the Autonomous Province of Bozen/Bolzano for the calculation of the degree of loss. The visual comparison of the two curves demonstrated the validity of the vulnerability curve.

The results (intensity and degree of loss) are displayed herein for the first time in two separate maps (Fig. 6) in order to demonstrate the spatial pattern of the two factors. By the maps it is clear that buildings located very close to the steep slope experienced higher intensity. For buildings situated next to the road also high intensity values were recorded, probably because roads acted as preferred corridors that enabled the debris flow to enter the settlement area. Moreover, in Fig. 6 is also obvious that in Ennewasser (north of the map) the intensities were significantly lower due to the protection offered by the forest on the east side of the settlement. In Fig. 6 (right map) the spatial distribution of the degree of loss follows in most cases the pattern of the intensity distribution. Table 1 clearly shows that the majority of the buildings experienced rather low intensity of debris flow (less than $1 \mathrm{~m}$ debris height). Only nine buildings $(17.5 \%)$ experienced high intensity of debris flow (more than $2 \mathrm{~m}$ debris height).

Observations based on the vulnerability curve may also lead to the selection of indicators: e.g. height of windows, proximity to the road, importance of surrounding vegetation. In more detail, since the curve becomes clearly steeper after the intensity of $1.5 \mathrm{~m}$ it reveals the importance not only of the existence of the openings but also of their height and possibly also size, material and location in relation to the flow 


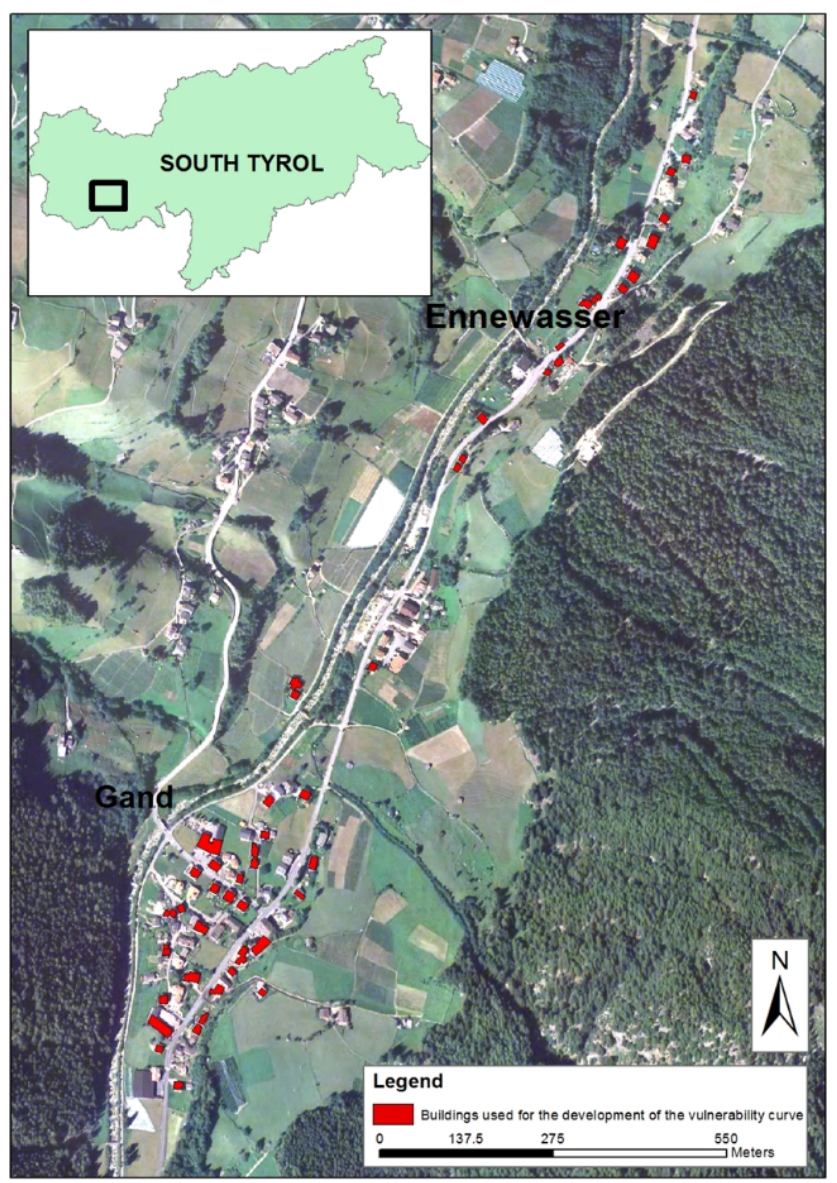

Figure 3. The case study area: municipality of Martell (villages of Gand and Ennewasser). The buildings used in the case study are highlighted in red colour.

direction. The vulnerability curve also shows that there are buildings (points) that, although they have experienced low intensities, have suffered a considerable degree of loss. This may be explained by the existence of basements or of basement windows that allowed material to enter the basement and cause additional damage to the building. However, the opposite phenomenon may be also observed. There are buildings that although they have experienced very high intensity, the degree of loss is relatively low. Since the degree of loss is a percentage of loss, buildings with more than one floor will experience a lower degree of loss as percentage of their overall value. This shows the importance of indicators concerning the number of floors or the height of the building.

\section{The application of the IBM in the study area}

The IBM was applied at the same buildings that were used for the computation of the vulnerability curve in Gand and Ennewasser (Municipality of Martell). Based on photographic documentation provided from the municipality of Martell a
Table 1. Intensity categories and the corresponding number of affected buildings.

\begin{tabular}{lrl}
\hline Intensity & $\begin{array}{r}\text { Number of } \\
\text { buildings }\end{array}$ & $\%$ \\
\hline$<1$ & 30 & 59 \\
$1-2$ & 12 & 23.5 \\
$>2$ & 9 & 17.5 \\
\hline
\end{tabular}

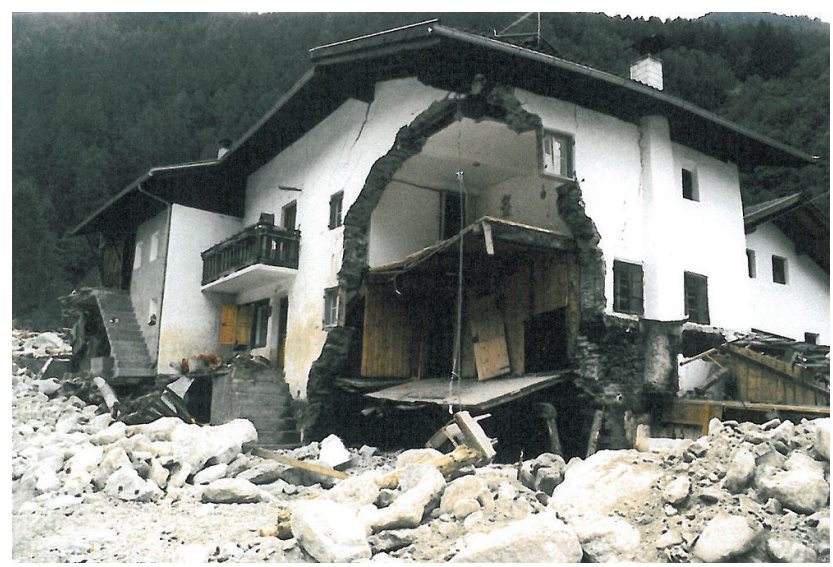

Figure 4. Example of photographic documentation following the August 1987 event (source: municipality of Martell).

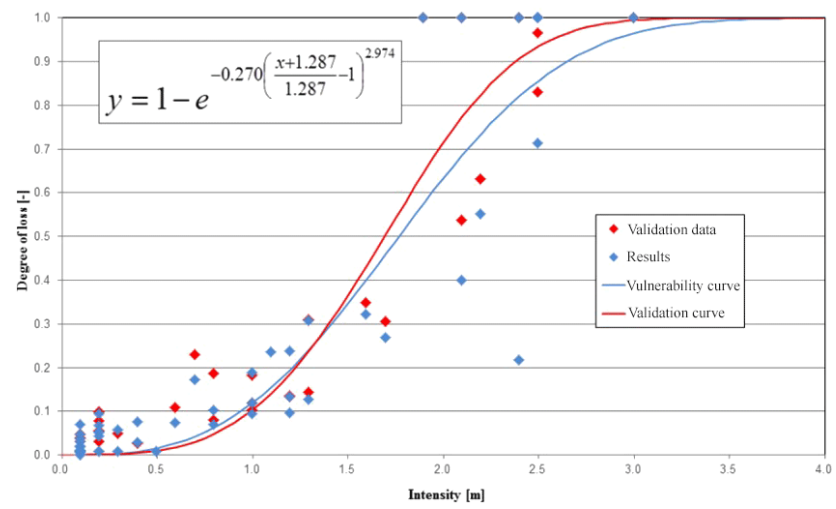

Figure 5. The vulnerability curve and the validation curve based on damage data from the 1987 debris flow event in Martell (South Tyrol) (Papathoma-Köhle et al., 2012).

GIS a database was developed containing the vulnerability indicators for each building. Information regarding the material, the building condition and the intensity could be collected from photos, whereas information regarding the building surroundings and the building location, in relation to the neighbouring buildings, could be acquired from an orthophoto of the area. An example of the calculation of physical vulnerability using indicators is shown in Fig. 7. The photo shows a building which was damaged from the debris flow in 1987. The intensity of the process and the degree of loss 

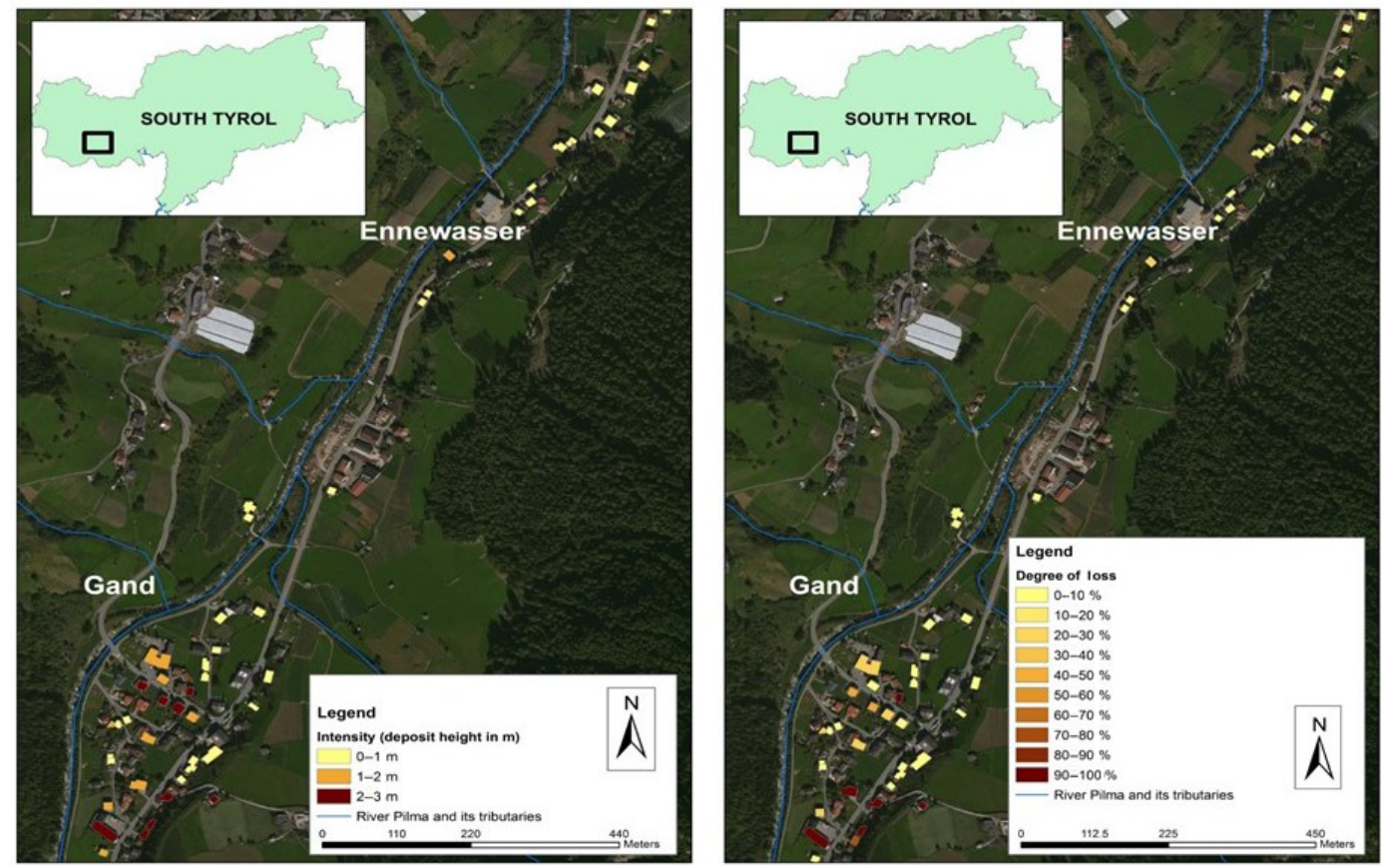

Figure 6. The spatial pattern of the assessed intensity of the 1987 event per building (left panel) and the corresponding degree of loss (right panel) in the villages Gand and Ennewasser.

have been assessed and calculated respectively during the development of the vulnerability curve (Papathoma-Köhle et al., 2012).

The vulnerability indicators were collected for each building, and as shown in the example of Fig. 7, $\mathrm{RVI}_{\mathrm{EP}}$ and RVIVR were calculated. The $\mathrm{RVI}_{\mathrm{EP}}$ is a relative vulnerability index that is important for professionals designing emergency evacuation plans. This may include local authorities or emergency services such as the fire brigade. The RVIVR is a relative vulnerability index that may indicate the buildings that need reinforcement or local protection measures in order to reduce their physical vulnerability to debris flow. This information may interest local authorities and individual building owners but also insurance companies. The application of the RVI at Martell shows that the weighting of the vulnerability indicators by different end users leads (at least in this case) to rather similar results (Figs. 8 and 9 and Table 2) and that differences are focused on individual buildings.

In the following paragraphs the results of the two methods are compared, the benefits and drawbacks of the indicators based method are listed and improvements not only for the further development of IBMs but also for the improvement of the assessment of physical vulnerability in general are outlined.

\section{Results and discussion}

\subsection{Comparison of the results of both methods}

The spatial distribution of damage and intensity data used for the development of vulnerability curves is not often displayed on a map, although this would be simple with the use of GIS. The curves are mainly used as a tool that displays geographically distributed information on a $x y$ axis system and may predict the degree of loss of a building should it experience a specific intensity. However, in the present article the spatial pattern of the intensity and the degree of loss are displayed in two maps in Fig. 6. The comparison of the results of the IBM (Fig. 8) with the intensity of the process per building of the 1987 event and the spatial distribution of the degree of loss (Fig. 6) (Papathoma-Köhle et al., 2012) shows that the results of both methods are generally compatible. The buildings that experienced a high degree of loss (Fig. 6) are often the ones with a high RVI, especially in the case of RVIVR. However, the visual comparison of the maps highlights some exceptions. Some buildings that experienced a very high degree of loss have been assigned with a low vulnerability index and vice versa. For example, the buildings in Ennewasser, which were confronted with low intensities and, for this reason, also suffered a relative lower degree of loss, were classified as highly vulnerable by the IBM. This observation highlights an important aspect of the method: the fact that the IBM is not hazard intensity specific, in contrast to the vulnerability curve method that includes information regard- 
Table 2. Comparison of the results per building. The typeface indicates the degree of intensity as described in Table 1 (bold for intensity $<1 \mathrm{~m}$, italic for intensities $1-2 \mathrm{~m}$ and underlined for intensities $>2 \mathrm{~m}$ ).

\begin{tabular}{|c|c|c|c|c|c|c|c|c|c|}
\hline $\begin{array}{l}\text { Building } \\
\text { ID }\end{array}$ & Intensity & $\begin{array}{l}\text { Degree } \\
\text { of loss }\end{array}$ & $\mathrm{RVI}_{\mathrm{VR}}$ & $\mathrm{RVI}_{\mathrm{EP}}$ & $\begin{array}{l}\text { Building } \\
\text { ID }\end{array}$ & Intensity & $\begin{array}{l}\text { Degree } \\
\text { of loss }\end{array}$ & RVIVR $_{\text {VR }}$ & $\mathrm{RVI}_{\mathrm{EP}}$ \\
\hline G 26 & $\underline{2.10}$ & $\underline{1.00}$ & $\underline{0.6565}$ & $\underline{0.88}$ & G 226 & 2.40 & $\underline{0.22}$ & $\underline{0.5055}$ & $\underline{0.565}$ \\
\hline G 28 & $\overline{1.20}$ & $\overline{0.10}$ & $\overline{0.6285}$ & $\overline{0.735}$ & G 41 & $\overline{0.10}$ & $\overline{0.04}$ & $\overline{\mathbf{0 . 4 3 3 5}}$ & $\overline{\mathbf{0 . 5 3}}$ \\
\hline G 29 & 2.40 & $\underline{1.00}$ & $\underline{0.6615}$ & $\underline{0.76}$ & G 219 & 0.10 & 0.02 & 0.5305 & 0.55 \\
\hline G 30 & $\overline{0.80}$ & $\overline{0.10}$ & $\overline{\mathbf{0 . 5 8 8 5}}$ & $\overline{0.665}$ & G 42 & 0.10 & 0.02 & 0.4305 & 0.51 \\
\hline G 32 & 2.50 & 0.71 & 0.6135 & 0.69 & G 45 & 0.20 & 0.05 & 0.4665 & 0.56 \\
\hline G 35 & 1.90 & 1.00 & 0.6285 & 0.735 & G 46 & 0.30 & 0.06 & 0.5605 & 0.62 \\
\hline G 36 & 0.20 & 0.07 & 0.5855 & 0.645 & G 60 & 0.20 & 0.01 & 0.5335 & 0.61 \\
\hline G 37 & 0.60 & 0.07 & 0.5855 & 0.645 & G 62 & 0.10 & 0.03 & 0.6035 & 0.64 \\
\hline G 38 & 0.10 & 0.00 & 0.6815 & 0.735 & M 68 & 0.10 & 0.05 & 0.6755 & 0.695 \\
\hline G 224 & 1.60 & 0.32 & 0.5985 & 0.71 & M 69 & 0.10 & 0.01 & 0.6945 & 0.805 \\
\hline G 47 & 0.10 & 0.01 & 0.6785 & 0.715 & E 148 & 0.50 & 0.01 & 0.6755 & 0.74 \\
\hline G 48 & 0.10 & 0.01 & 0.6315 & 0.755 & E 153 & 0.10 & 0.01 & 0.6485 & 0.7 \\
\hline G 49 & 0.10 & 0.01 & 0.6215 & 0.705 & E 154 & 1.30 & 0.31 & 0.6755 & 0.74 \\
\hline G 55 & 1.10 & 0.24 & 0.6945 & 0.805 & E 157 & 0.10 & 0.01 & 0.5845 & 0.655 \\
\hline G 54 & 0.20 & 0.04 & 0.5905 & 0.65 & E 159 & 0.20 & 0.01 & 0.6355 & 0.765 \\
\hline G 225 & 0.10 & 0.01 & 0.6855 & 0.745 & E 160 & 0.30 & 0.01 & 0.6855 & 0.745 \\
\hline G 52 & 1.00 & 0.19 & 0.5565 & 0.65 & E 161 & 1.00 & 0.12 & 0.6755 & 0.695 \\
\hline G 53 & 1.70 & 0.27 & 0.5145 & 0.625 & E 162 & 0.40 & 0.08 & 0.6455 & 0.68 \\
\hline G 56 & $\underline{3.00}$ & $\underline{1.00}$ & $\underline{0.5785}$ & $\underline{0.615}$ & E 221/A & 0.20 & 0.09 & 0.6885 & 0.765 \\
\hline G 57 & $\overline{1.20}$ & $\overline{0.24}$ & $\overline{0.4885}$ & $\overline{0.565}$ & E $221 / B$ & 0.20 & 0.05 & 0.6755 & 0.695 \\
\hline G 59 & $\underline{2.50}$ & $\underline{1.00}$ & $\underline{0.6685}$ & $\underline{0.745}$ & E 170 & 0.80 & 0.07 & 0.5385 & 0.635 \\
\hline G 58 & $\overline{2.50}$ & $\overline{1.00}$ & $\underline{0.5785}$ & $\overline{0.615}$ & E 171 & 0.70 & 0.17 & 0.6885 & 0.765 \\
\hline G 66 & 2.10 & $\overline{0.40}$ & $\underline{0.5785}$ & $\overline{0.615}$ & E 172 & 1.00 & 0.10 & 0.6755 & 0.695 \\
\hline G 65 & 1.30 & 0.13 & 0.6085 & 0.685 & E 173 & 0.40 & 0.03 & 0.6655 & 0.69 \\
\hline G 64 & 2.20 & $\underline{0.55}$ & $\underline{0.5035}$ & $\underline{0.54}$ & E 176 & 0.10 & 0.07 & 0.6585 & 0.75 \\
\hline G 63 & $\overline{1.20}$ & $\overline{0.13}$ & $\overline{0.4885}$ & $\overline{0.585}$ & & & & & \\
\hline
\end{tabular}

ing the intensity. It is clear that the two approaches define vulnerability in a different way, namely as a result of intrinsic characteristics in one case (IBM) or as a consequence of a specific hazard intensity in the other (vulnerability curves). In contrast, there are buildings in Gand that, although they have experienced a high degree of loss, are assigned with a low RVI. The high degree of loss is expected since, according to Fig. 6, the same building also experienced high intensity. It is, therefore, clear that the results show inconsistencies because the intensity is not considered by the IBM. Nevertheless, some vulnerability indicators are directly connected to the intensity that a building experiences, e.g. surrounding vegetation or protection from other buildings or proximity to the road network.

By visualising the spatial pattern of the degree of loss and the observed intensity, as well as their relationship through vulnerability curves, additional valuable information regarding the importance of vulnerability indicators may become available and, in this way, the IBM may be modified, extended and substantially improved. For example, the low intensities recorded on buildings in Ennewasser may be related to the presence of surrounding vegetation, which highlights the importance of the relevant vulnerability indicator. This leads to the conclusion that both methods, although based on a different concept, shed light on two different aspects of the physical vulnerability: specifically, the intrinsic characteristics of the buildings and the expected degree of loss under a given intensity respectively; therefore, they should be used in combination rather than in conflict. Apart from the visual comparison of the results, a closer look to the results for each building in Table 2 reveals even more about the advantages and disadvantage of both methods.

In Table 2 the results of both methods are displayed for each of the 51 buildings of the case study. The comparison of the results leads to a number of interesting observations.

1. The RVI values vary from 0.43 to 0.88 . No extreme values are observed. There are no buildings with RVI $=1$. This is to be expected since there are no buildings in the area with extreme scores (e.g. material = wood or condition $=$ ruin).

2. There are no buildings with $\mathrm{RVI}=0$. That would mean that a building is not vulnerable. However, the assignment of zero scores that could lead in such a result is not possible. This is understood since no building can be characterised by zero vulnerability since all buildings 


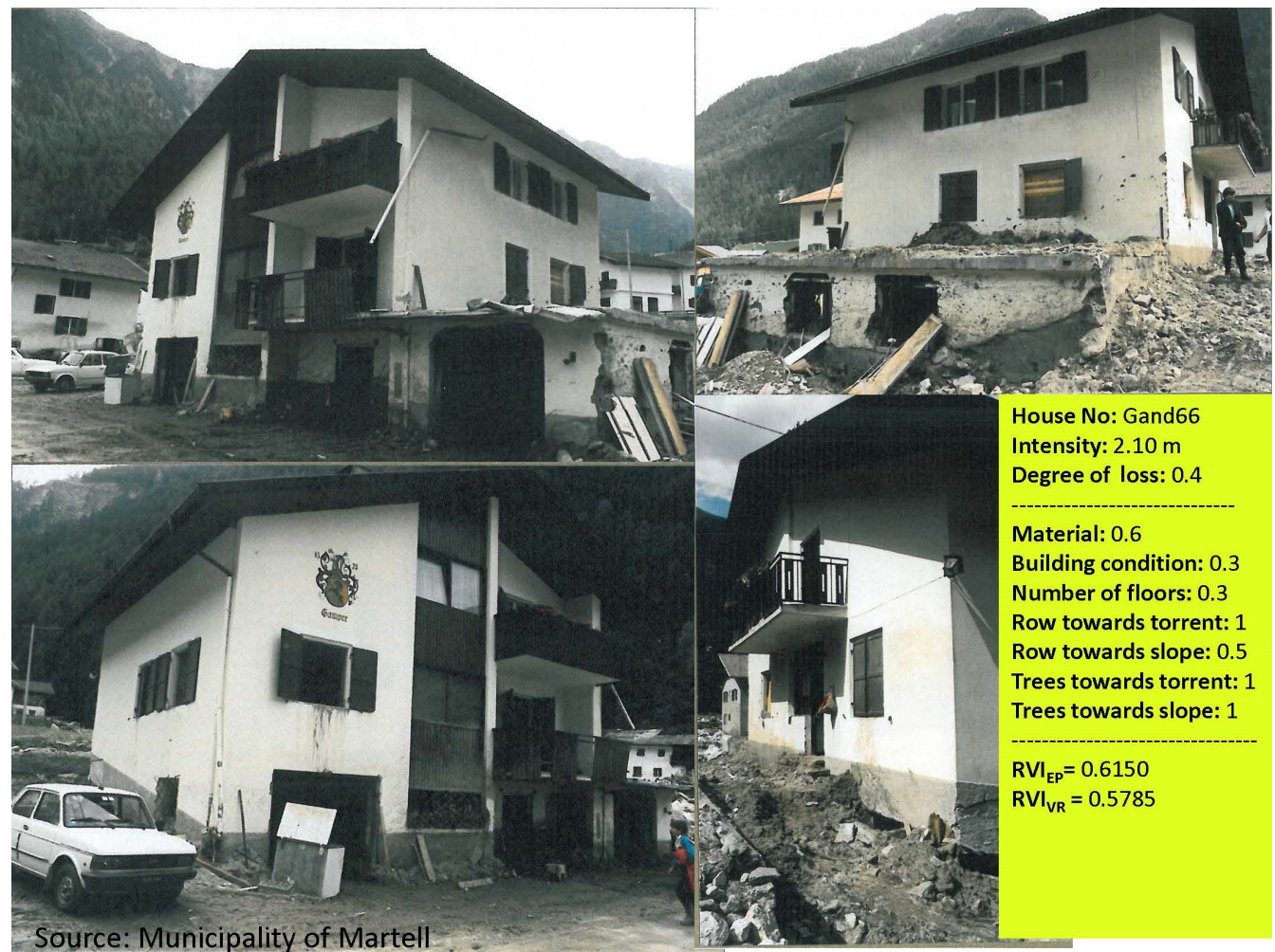

Figure 7. An example of the application of the IBM for two different objectives: for evacuation planning (RVIEP) and for vulnerability reduction strategies and reinforcement $\left(\mathrm{RVIVR}_{\mathrm{V}}\right)$.
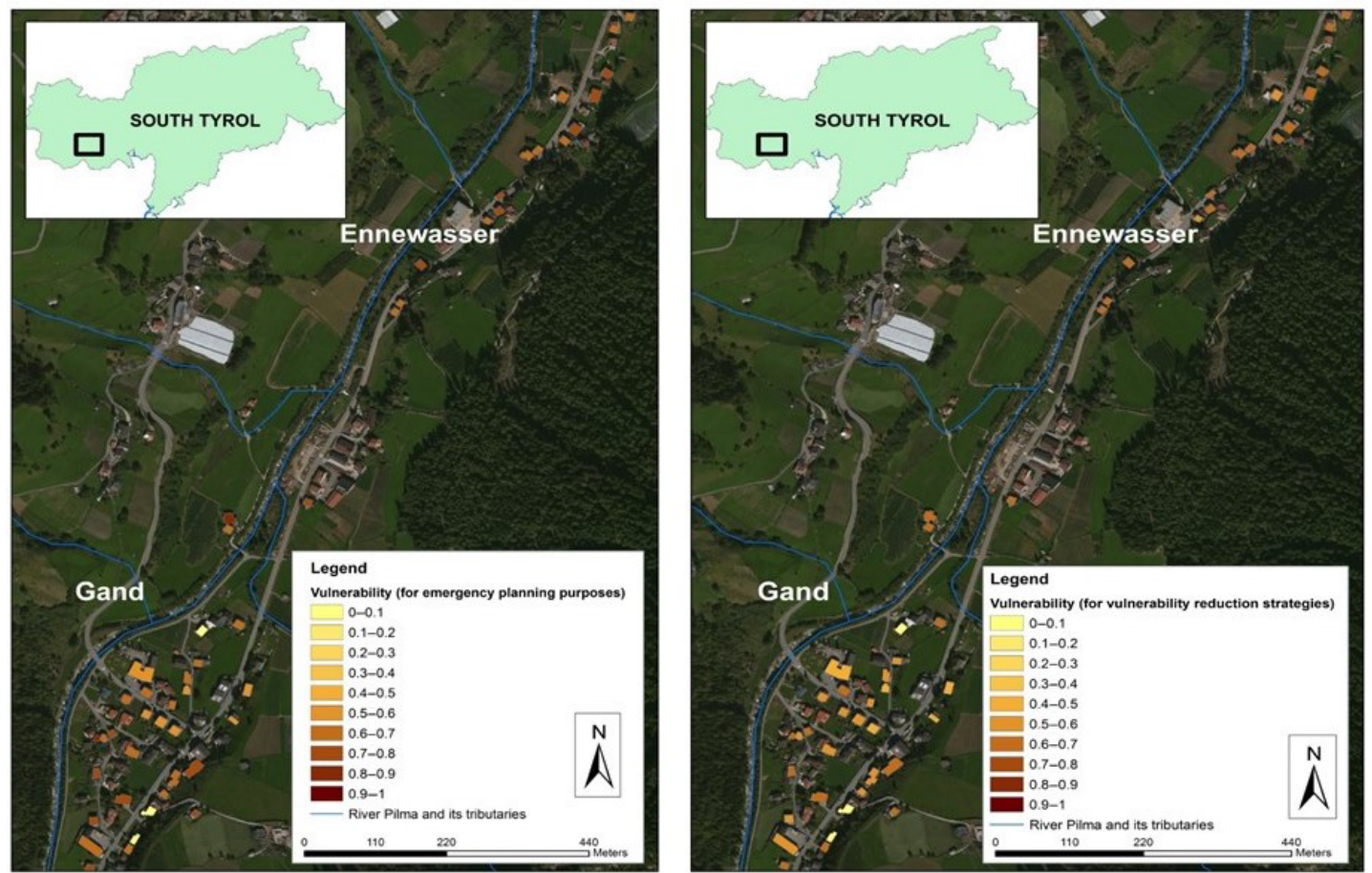

Figure 8. The spatial distribution of physical vulnerability using indicators for emergency planners (left panel) and for vulnerability reduction strategies (right panel). 
under investigation are located within the area affected by the debris flow. This is also supported by the vulnerability curve, which is based on a real event and shows that no building suffered 0 degrees of loss.

3. As far as the comparison between the two methodologies is concerned, some buildings, although they experienced low degree of loss, are assigned a high RVI. This can be explained by the fact that the IBM is not intensity specific. The high RVI means that the specific building could experience a high degree of loss due to its characteristics. However, the vulnerability curve shows that the specific building did not suffer a high degree of loss during the event for reasons that may be connected to characteristics of the process itself (e.g. G48). This is even more obvious in the case of buildings G53 and G56. The two buildings have been assigned with similar RVIs. They have, however, experienced degrees of loss of 1 and 0.27 respectively. This is explained by the significant difference in the process intensity (1.7 and $3 \mathrm{~m}$ respectively).

4. However, the contrary observation is also evident: some buildings have been impacted by debris flow of high intensity which resulted in a low degree of loss (e.g. G53, G64, G66, G224, G226). Obviously, the fact that buildings, although they experience the same intensity of the process, experience different degrees of loss (some are completely destroyed and some others have less than $50 \%$ of loss) may be explained by significant differences in their attributes. However, another explanation may be related to characteristics of the process that are not considered by the vulnerability curve, such as velocity of the flow, direction of impact, viscosity, duration, size of debris, etc.

The results of the IBM depend on the set of indicators used for the calculation of the RVI. The IBM is based on a set of indicators that were selected based on expert judgement, damage reports and photographic documentation of past events. However, Birkmann (2006), based on existing sets of indicators (EEA, NZ Statistics etc.), provides a list of the quality criteria that vulnerability indicators have to fulfil. In Table 3 the set of indicators of the present study is tested towards some of these criteria.

Table 3 shows that although the set of indicators fulfils many criteria, there is still room for improvement of the indicator set itself, the description and assignment of the scores for each indicator and the collection of the required data.

\subsection{Benefits, limitations and future development of the IBM}

In contrast to the vulnerability curves, IBMs are not established and applied by practitioners in the same dimension. For this reason, the comparison between the two concepts is not only essential but also very challenging due to the different way that they approach vulnerability. However, this comparison may highlight the benefits of the IBMs, point out its weaknesses and lead to a list of recommendations not only for the improvement of the indicator-based concept but also for the improvement of the assessment of physical vulnerability in the future.

The comparison of the two methods highlighted the following benefits of using indicators for assessing physical vulnerability of buildings to torrential hazards.

1. Contrary to vulnerability curves, the IBM prompts the user to develop an inventory of the elements at risk and a database of building characteristics. This may enable the development of strategies for the reduction of vulnerability at a very local level, as well as the development of local structural protection measures. In this way, the focus and the resources will be concentrated on limited amount of buildings.

2. The IBM does not use empirical loss data but rather indicates the relative vulnerability of individual buildings. This means that this type of methodology can be applied to areas with no recorded history of events, making its use possible in the absence of damage data. In other words, although the IBM does not have a predictive power in quantifying expected loss in comparison to the vulnerability curves, it does still have a predictive power in indicating the specific buildings that will experience loss.

3. The weighting is flexible and may be adjusted to the needs of individual users. This ensures the use of the methodology by a range of end users.

4. No experts are required for the data collection. The assignment of the scores of the individual indicators do not require any expert knowledge. This means that even the owners of the buildings may provide the required information themselves, saving in this way money and time for data collection.

5. The use of GIS makes the updating of information easier but, by changing the scores of indicators, we can also answer "what if" questions related to local structural protection and reinforcement of buildings. The weights and scores may be fine-tuned by using information of past events. Moreover, by using easy to update databases future changes in the spatial pattern of the built environment, socioeconomic and land use changes may be considered for future scenarios.

6. The use of GIS enables the visualisation of the spatial pattern of the physical vulnerability and also individual characteristics (Fuchs et al., 2012). In this way, vulnerability maps may be used as a basis e.g. for emergency 
Table 3. Quality criteria for vulnerability indicators (adapted from Birkmann, 2006).

\begin{tabular}{|c|c|}
\hline Criteria & Vulnerability indicators \\
\hline Measurable & $\begin{array}{l}\text { The indicators used are not always easily measurable. The difference between a building of "good" and } \\
\text { "medium" condition is not clear and not measurable in quantitative terms. The scores for each building } \\
\text { may be dependent on the judgement of the data collector and may not always be objective. Moreover, } \\
\text { this information is process specific. The scoring of the same indicators would be different for a study } \\
\text { focusing e.g. on earthquakes. Improved data collection techniques (e.g. detailed standardised } \\
\text { questionnaires) may improve the measurability of the indicators. }\end{array}$ \\
\hline Relevant & $\begin{array}{l}\text { The indicators have been based on reports and documentation of past events and for this reason are } \\
\text { relevant to the assessment. They have also been chosen according to the needs of the end users } \\
\text { although the latter could be more involved in the selection process in the future. The weighting, } \\
\text { however, is done directly by the end users, offering flexibility to the method as well as subjectivity. }\end{array}$ \\
\hline Policy-relevant & $\begin{array}{l}\text { Although not demonstrated in the specific article, the indicators may be policy relevant. The } \\
\text { vulnerability indicators may give decision makers an overview of damage potential for future events. } \\
\text { Moreover, they may be used for emergency planning and they may guide local structural protection } \\
\text { measures as shown by Holub and Fuchs (2009) for case studies in the Austrian Alps. However, } \\
\text { intensity should also be included in the assessment. }\end{array}$ \\
\hline $\begin{array}{l}\text { Measure } \\
\text { important }\end{array}$ & $\begin{array}{l}\text { The indicators are connected to key elements (e.g. reaction of the structure to the impact of debris } \\
\text { flow) and are not attempting to indicate all aspects (e.g. vulnerability to other hazard types); however, } \\
\text { they do not consider the intensity of the process. }\end{array}$ \\
\hline $\begin{array}{l}\text { Analytically and } \\
\text { statistically sound }\end{array}$ & $\begin{array}{l}\text { Although the indicators may give an overview of the actual situation, the links between natural process } \\
\text { and degree of loss, as well as the reaction of a structure to the natural process according to its } \\
\text { characteristics, are not fully understood and, therefore, further research is required (Mazzorana et al., } \\
\text { 2014). }\end{array}$ \\
\hline $\begin{array}{l}\text { Understandable/ } \\
\text { easy to interpret }\end{array}$ & $\begin{array}{l}\text { The indicators used in this study are easy to interpret. No experts are required for their collection. } \\
\text { Although this is an advantage of the method, the judgement of the collector may influence the result } \\
\text { significantly and increase uncertainties. }\end{array}$ \\
\hline Sensitivity & $\begin{array}{l}\text { Although the indicators are specific to the phenomenon of debris flow, they are not sensitive to changes } \\
\text { related to this phenomenon (e.g. intensity). However, they are sensitive to changes in the structure of } \\
\text { the building, which means that they are able to express changes in the physical vulnerability should a } \\
\text { building be reinforced. }\end{array}$ \\
\hline Validity/accuracy & $\begin{array}{l}\text { The indicators have the capacity to express the physical vulnerability of buildings in most of the cases } \\
\text { and this may also be confirmed by the results of the vulnerability curve. However, this is not always } \\
\text { the case. The cases where high vulnerability has been assigned for buildings that have experienced } \\
\text { low degree of loss have to be investigated, and based on the conclusions of this investigation the } \\
\text { methodology may be improved. }\end{array}$ \\
\hline Reproducible & $\begin{array}{l}\text { Theoretically, the set of indicators could be reproducible for another area facing a threat of debris } \\
\text { flows. However, significant differences in the architecture and building standards of buildings should } \\
\text { be considered. }\end{array}$ \\
\hline $\begin{array}{l}\text { Based on } \\
\text { available data }\end{array}$ & $\begin{array}{l}\text { The indicators are not always based on available data. Some information could be available from the } \\
\text { municipality. However, the majority of the required information may be collected through field work } \\
\text { or interpretation of ortho-photos. }\end{array}$ \\
\hline $\begin{array}{l}\text { Data } \\
\text { comparability }\end{array}$ & $\begin{array}{l}\text { The indicators may be compared to similar ones in other areas but also to past or future conditions of } \\
\text { the same area. }\end{array}$ \\
\hline Cost effective & $\begin{array}{l}\text { The indicators are cost effective. The assessment of the vulnerability for debris flow usually involves } \\
\text { a limited amount of buildings. Although fieldwork is necessary there are ways to avoid it by sending } \\
\text { questionnaires to the building owners or interpreting ortho-photos for rapid data collection. }\end{array}$ \\
\hline
\end{tabular}


planning. On the contrary, practitioners use vulnerability curves as a prediction tool rather than to acquire information about specific buildings in an area and for this reason they ignore their spatial component.

7. The transferability of methods in the field of risk research may be challenging due to differences in the nature of elements at risk, environmental conditions and processes. However, since the specific method is not process intensity dependent, it is easier to transfer it to other areas with a similar problem provided that necessary modifications will be made (e.g. additional building characteristics due to local architecture).

8. IBMs encourage the involvement of local communities and individual building owners in data collection and vulnerability reduction (Thaler and Levin-Keitel, 2016; Thaler et al., 2016).

However, IBMs for physical vulnerability assessment are in their infancy, allowing much room for improvement. The first step for their improvement is the identification of the following main drawbacks of the methodology.

1. Intensity relevance: the IBM assigns a relevant vulnerability index to each building which more or less shows which building is more vulnerable than another in a worse-case scenario without indicating a specific intensity of the event. This is a major drawback which is obvious from Table 2: buildings with high RVI experienced a very low degree of loss. A possible development of the method could be similar to the one of PTVA-2, which included the water height (in this case the deposit height) as an indicator in the vulnerability assessment, based on a specific scenario.

2. Completeness of the set of indicators: in Table 2 some inconsistencies between the two methods for specific buildings are evident. The reason may be the lack of completeness of the set of indicators. For example, characteristics that may affect the vulnerability of the buildings significantly, such as the existence of openings on the slope side, their size and quality, as well as the existence of a basement are not considered.

3. Completeness of datasets and costs of data collection: the dataset required for the implementation of the methodology is detailed and has to be collected at local level.

4. Description of scores: the scores for the various indicators are often described in a trivial way, e.g. "good" or "medium" building condition, leading to a large dependence on the judgement of the data collector to decide the score that will be assigned to a building.

5. Classification of results: the classification of the results may also change the overview of the spatial pattern of the values. The classification method used in the present study was the "equal interval classification method" whereas, Kappes et al. (2012) used the "quantile classification methods", arguing that in this way the users may set priorities. In any case the classification method as well as the weighting should also be decided by the user.

6. "Relativeness" of the vulnerability index: the RVI expresses the relative vulnerability of buildings in an area. That means that the RVI points out which building is more vulnerable than the other without having the capacity to translate this vulnerability into a quantitative value. This may be considered a disadvantage for practitioners because the vulnerability map made this way may only indicate vulnerable buildings in an abstract way and vulnerability maps from different areas may not be compared.

7. Uncertainties: both methods bear a number of uncertainties that should be analysed and quantified. As far as the end users are concerned, decision makers are in need of vulnerability assessment methods that they can use for risk analysis but they also need to know the uncertainties that are associated with the vulnerability values. This is important because low estimated risk with high uncertainties may cause higher losses than medium estimated risks with minor uncertainties. Papathoma-Köhle et al. (2012) lists the sources of uncertainties that are related to the development of the vulnerability curve.

a. Intensity of the event: attributes of the intensity of the process such as duration, velocity, and direction are ignored.

b. Damage pattern: photographic documentation has been used for the identification of the damage pattern. Information regarding the damage of the interior of the buildings is missing.

c. The degree of loss was based on the assessment of the cost of reconstruction and the value of the building. Both assessments bear a significant number of uncertainties (e.g. existence and size of basement changes the building value, impact on the electricity and heating network).

d. Credibility of existing data: some buildings, although they were not severely damaged, got full compensations to be rebuilt due to relocation.

As far as the IBM is concerned, uncertainties are related to the following:

a. the subjectivity of the data collector (e.g. what is a "good" and what is a "medium" building condition?)

b. the subjectivity of the end user concerning the weighting and the classification method. 
Efforts to analyse and quantify uncertainties concerning the assessment of physical vulnerability for debris flows have been made in the past (Eidsvig et al., 2014; Totschnig and Fuchs, 2013); however, most of them concern vulnerability curves.

Based on the comparison of the two methods and the outline of the advantages and disadvantages of it as far as the assessment of physical vulnerability is concerned a number of recommendations for improvement may be made.

1. Reduction of data collection effort and time through the use of modern technologies (GIS and remote sensing): information regarding the surroundings or the building row is easily collected by using GIS maps and/or remote sensing where needed. For other types of information such as openings, existence of basement and building material and condition an additional field survey may be necessary. Alternative data collection methods (e.g. distribution of standardised questionnaires to the building owners) may also be introduced.

2. Improvement of post-disaster documentation methods: detailed post-disaster documentation including photographic material may provide valuable information regarding the interaction between natural processes and elements at risk but it may also give information regarding the variation of the intensity of a process within a given area. An improved method for damage documentation is recommended by Papathoma-Köhle et al. (2015).

3. Reconsider the score description: some scores would be more reliable if they were less dependent on expert judgment (for example building condition). A solution would be to reconsider their descriptions or propose tangible scores instead (e.g. age of the building or detailed description of building condition).

4. Additional indicators: the list of indicators used for the assessment of physical vulnerability of buildings to debris flow is not exhaustive. Information regarding the presence of a basement as well as the number, location, size and quality of openings is also missing. Furthermore, data on local structural protection of buildings (e.g. elevation, splitting wedges, deflection walls) should also be included.

5. Physical resilience: some of the indicators mentioned above may contribute not only to the assessment of the physical vulnerability of the building but also to the assessment of its physical resilience. According to Haigh (2010) a resilient built environment should "enable society to continue functioning when subject to a hazard". In this respect, when the interior of the building has been invaded by debris or when the heating and electricity network are located in the basement and have been heavily damaged by intruding water and material, the building will need more time to be re-inhabited by its occupants. Therefore, indicators regarding the physical resilience of buildings may include location of vital equipment, existence of openings, local protection measures, basement, primary or secondary residence of the inhabitants.

6. The interaction of structures with the natural process has not been thoroughly investigated. Gems et al. (2016) investigate the interaction among buildings and debris flow and they give insights of the impact of flooding in the interior and on the exterior of the building. However, further experiments are needed.

7. Improved weighting of indicators: the weighting of indicators is based on expert judgement increasing in this way the level of uncertainty. An improved weighting could base the hierarchy of indicators on statistical analysis of their importance correlating real damage data (monetary cost of damages) to building characteristics. Moreover, as mentioned earlier, a sensitivity analysis could be an additional next step of this study.

8. Application for multi-hazards: Kappes et al. (2012) presented the specific methodology for multi-hazards. In their study they made three separate maps based on the indicator-based methodology for flood, shallow landslides and debris flows. However, as Kappes et al. (2012) also pointed out, there is a need to consider how different hazard types affect the vulnerability of buildings to other hazards that may happen simultaneously or in a short time span. A database which includes indicators related to more than one hazard type would be a good start.

Improving the IBM is an important step towards disaster risk reduction; however, the advantages of the vulnerability curves are also indisputable. Therefore, a comparison of the two methods may reveal their advantages and drawbacks and may also inform the practitioners about their available methodological choices. However, as it is suggested in the following paragraphs, since both methodological approaches are important, a combination of the two may be the key to an improved physical vulnerability assessment approach.

\subsection{Vulnerability curves vs. vulnerability indicators: a new framework for physical vulnerability}

The above comparison of the two methodological concepts clearly shows that decision makers and other potential end users are actually in need of both methods during the four phases of the disaster management cycle for various reasons. An effort to place the available methodological concepts (including in this case also vulnerability matrices) within the phases of the disaster cycle has been made by PapathomaKöhle and Ciurean (2014). Figure 9 additionally shows the importance of vulnerability assessment in every phase of the 


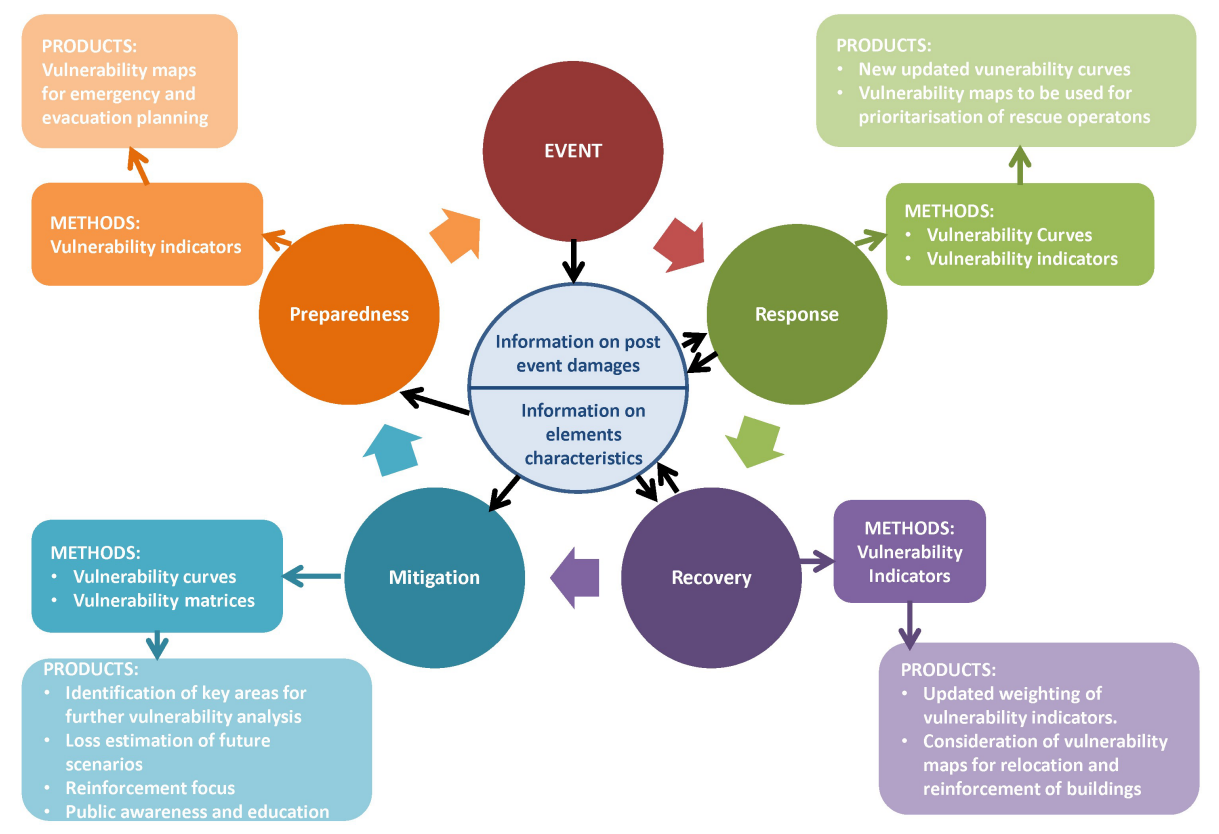

Figure 9. The role of vulnerability assessment and the corresponding methodological concepts in the phases of the disaster cycle (PapathomaKöhle and Ciurean, 2014).

disaster cycle, highlighting the relevant methods for each phase. For example, during the mitigation phase vulnerability curves may be used for the loss estimation of future events and the design of mitigation measures. The results in this case may be used for public awareness and education as well as for recommendations for reinforcement. However, vulnerability maps based on the vulnerability indicators may guide the emergency and evacuation planning process during the preparedness phase. Additionally, during the response phase, vulnerability maps are essential to indicate the buildings that are more likely to have been damaged, whereas the recovery phase is the ideal phase for validating the weighting of indicators. Moreover, during the recovery phase the results of the vulnerability assessment may be used as guidance for relocation of buildings. The centre of the disaster management cycle consists of an information pool including two types of data: empirical data from past events and an inventory of the elements at risk and their characteristics. The exchange of information between the pool and the different phases of the disaster cycle is also demonstrated in Fig. 9 through the black arrows.

In short, decision makers, authorities and disaster managers need a quantitative representation of physical vulnerability based on empirical data (curves) as well as relative vulnerability values for individual elements that are directly connected to their characteristics (indicators) and may support prioritisation of resources and small local interventions for vulnerability reduction. The fact that both approaches are significant stresses the need for a "holistic physical vulnerability framework for practitioners" that will enable practi- tioners not only to choose the relevant method according to their aim and the available resources but also to make full use of the fact that they both complement each other.

The interactions and possibilities for combination of the approaches should be included in a "holistic physical vulnerability framework for practitioners" (Fig. 10).

The framework consists of two major parts. The left one represents the empirical, ex post part, following the occurrence of a debris flow, and the right one is the ex ante part referring to the time period before a hazard occurs. The left part is connected to the use and development of vulnerability curves and the right one relates to the use of IBMs. Between them there are two main exchange possibilities, namely the updating of indicators and the refinement of their weighting through information derived from empirical data. In other words, based on empirical data of real events new indicators may be identified and the weighting of existing ones may be improved since damage data provide information on the interaction of buildings and natural processes and the role that structural characteristics may play as far as the consequences are concerned. On the right side, the framework lists the vulnerability indicators in several categories, recognising that some of them are closely connected to the intensity, such as the surroundings and the building row towards the river or towards the slope. A group of indicators related to resilience is also added. The challenge of involving the intensity of the process in the IBM is also tackled by introducing a "scenario" based on data provided from the empirical side of the framework. The scenario may be based on a specific past event and it should include information regarding 


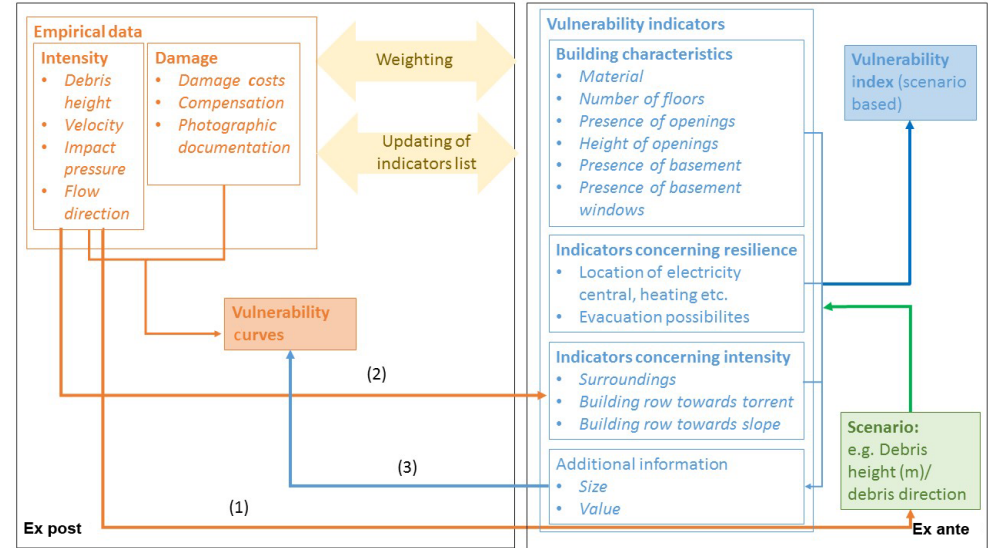

Figure 10. A preliminary framework for the assessment of physical vulnerability (adapted for debris flow hazards) showing clearly the need for exchange and interaction between the two methodological approaches.

Table 4. Indicators for a scenario of $1.5 \mathrm{~m}$ debris height intensity and flow coming from the slope and not the river side.

\begin{tabular}{|c|c|c|c|c|}
\hline & Indicator & Variable & $\begin{array}{l}\text { Vulnerability } \\
\text { score }\end{array}$ & Justification of score \\
\hline \multirow{13}{*}{ 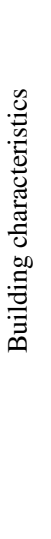 } & \multirow{3}{*}{ Material } & Adobe & 1 & \multirow{3}{*}{ Expert judgement } \\
\hline & & Brick 0.5 & 0.5 & \\
\hline & & Reinforced 0.1 & 0.1 & \\
\hline & Number of floors & One floor & 0.7 & Debris height (scenario) \\
\hline & \multirow{3}{*}{ Presence of openings } & & & \multirow{3}{*}{ Flow direction (scenario) } \\
\hline & & Slope side & 0.9 & \\
\hline & & River side & 0.2 & \\
\hline & \multirow{2}{*}{ Height of openings } & $h<1.5 \mathrm{~m}$ & 0.9 & \multirow{2}{*}{ Debris height (scenario) } \\
\hline & & $h>1.5 \mathrm{~m}$ & 0.1 & \\
\hline & \multirow{2}{*}{ Presence of basement } & Yes & 0.8 & \multirow{2}{*}{-} \\
\hline & & No & 0.2 & \\
\hline & \multirow{2}{*}{ Basement windows } & Yes 1 & 0.9 & \multirow{2}{*}{-} \\
\hline & & No 0 & 0.1 & \\
\hline \multirow{11}{*}{ 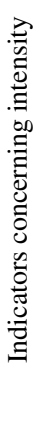 } & \multirow{5}{*}{ Surroundings } & Wall $>1.5 \mathrm{~m}$ & 0.1 & \multirow{5}{*}{ Debris height and flow direction (scenario) } \\
\hline & & Wall $<1.5 \mathrm{~m}$ & 0.3 & \\
\hline & & Vegetation (trees) & 0.5 & \\
\hline & & Vegetation (bushes) & 0.7 & \\
\hline & & No protection & 0.9 & \\
\hline & \multirow{3}{*}{ Building row towards river } & First & 0.3 & \multirow{3}{*}{ Flow direction } \\
\hline & & Second & 0.3 & \\
\hline & & $>$ Third & 0.3 & \\
\hline & \multirow{3}{*}{ Building row towards slope } & First & 0.9 & \multirow{3}{*}{ Flow direction } \\
\hline & & Second & 0.7 & \\
\hline & & $>$ Third & 0.4 & \\
\hline \multirow{8}{*}{ 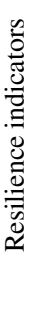 } & \multirow{3}{*}{ Location of heating } & Basement & 0.9 & \multirow{3}{*}{-} \\
\hline & & First floor & 0.5 & \\
\hline & & Second floor or higher & 0.1 & \\
\hline & \multirow{3}{*}{ Location of electricity central } & Basement & 0.9 & \multirow{3}{*}{-} \\
\hline & & First floor & 0.5 & \\
\hline & & Second floor or higher & 0.1 & \\
\hline & \multirow{2}{*}{ Evacuation possibilities } & Only one floor & 0.8 & \multirow[b]{2}{*}{-} \\
\hline & & More floors & 0.2 & \\
\hline
\end{tabular}


not only the debris height per building but also the direction of the flow and, ideally, the impact pressure or the velocity of the flow. This is the first "interaction" between the two sides (1). Information on the intensity of the event is also used to inform the group of indicators related to the intensity (2). The scores of the variables for each indicator will be formed according to the scenario as it is indicatively demonstrated in Table 4. In the same way, exchange of information is necessary in the other direction. Information regarding the buildings is also needed for the development of a vulnerability curve since data concerning the size and the value of the building are necessary for the calculation of the degree of loss (3). By using a specific scenario, the calculation of the IBM is not anymore intensity independent and the prediction capability of the method increases. Moreover, in contrast to the curves, additional information on the process, such as the flow direction, may be used.

The framework of Fig. 10 could be further improved by including more detailed information about their weighting and their aggregation to an index, possibilities for the identification of uncertainties and their quantification, as well as the consequences of change (climate and socioeconomic to both sides of the framework).

\section{Conclusions}

Vulnerability assessment constitutes a large part of risk analysis and its reduction has a direct effect on the consequences of natural disasters on lives, livelihoods, communities, buildings and infrastructure. The various methods available are used mostly until now in isolation. In this article, an IBM methodology is applied and scrutinised, enabling the comparison between two large groups of approaches. The vulnerability curves, although widely used by practitioners reveal the need to include the characteristics of the buildings (indicators) in the assessment of physical vulnerability. However, the IBM presented and applied in the present article shows that although assessing physical vulnerability using indicators may give reliable results, significant work has to be done in order to improve the use of IBMs for physical vulnerability assessment. Finally, the article emphasises that there is no need for new methodologies as far as the assessment of physical vulnerability is concerned. In contrast, there is a need not only to improve the existing ones but also to combine them in order to exploit their full power. The need for a "holistic framework for physical vulnerability assessment for practitioners" is emphasised and a preliminary version of this framework is presented. The framework offers the opportunity to the end users to use both methodologies in a complementary way; however, in the future it should include additional steps for the quantification of uncertainties and the consideration of change, not only as far as the natural process is concerned (climate change) but also socioeconomic and land use changes that will have a direct influence on the consequences of natural hazards.

Acknowledgements. This project received funding from the Austrian Science Fund (FWF): P 27400. Data collection was partly supported by the EU project MOVE (Methods for the Improvement of Vulnerability Assessment in Europe) (contract number 211590). The author would like to thank the Local Authorities of Bolzano and the Municipality of Martell for the provision of data and photographic material. Furthermore, Thomas Thaler and Sven Fuchs are thanked for the discussions on earlier drafts of the present article.

Edited by: T. Glade

Reviewed by: two anonymous referees

\section{References}

Adger, N. W., Brooks, N., Bentham, G., Agnew, M., and Eriksen, S.: New indicators of vulnerability and adaptive capacity, Tyndall Centre for Climatic Research, Tyndall, 2004.

Balica, S. F., Douben, N., and Wright, N. G.: Flood vulnerability indices at varying spatial scales, Water Sci. Technol., 60.10, 25712580, 2009.

Barnett, J., Lambert, S., and Fry, I.: The Hazards of Indicators: Insights from the Environmental Vulnerability Index, Ann. Assoc. Am. Geogr., 98, 102-119, 2008.

Barroca, B., Bernardara, P., Mouchel, J. M., and Hubert, G.: Indicators for identification of urban flooding vulnerability, Nat. Hazards Earth Syst. Sci., 6, 553-561, doi:10.5194/nhess-6-5532006, 2006.

Birkmann, J.: Indicators and criteria for measuring vulnerability: Theoretical bases and requirements, in: Measuring Vulnerability to Natural Hazards: Towards disaster resilient societies, edited by: Birkmann, J., UNU Press, Tokyo, 2006.

Cutter, S., Boruff, B. J., and Shirley, W. L.: Social Vulnerability to Environmental Hazards, Social Sci. Quart., 84, 242-261, 2003.

Dall'Osso, F., Gonella, M., Gabbianelli, G., Withycombe, G., and Dominey-Howes, D.: A revised (PTVA) model for assessing the vulnerability of buildings to tsunami damage, Nat. Hazards Earth Syst. Sci., 9, 1557-1565, doi:10.5194/nhess-9-1557-2009, 2009a.

Dall'Osso, F., Gonella, M., Gabbianelli, G., Withycombe, G., and Dominey-Howes, D.: Assessing the vulnerability of buildings to tsunami in Sydney, Nat. Hazards Earth Syst. Sci., 9, 2015-2026, doi:10.5194/nhess-9-2015-2009, 2009b.

Dall'Osso, F., Maramai, A., Graziani, L., Brizuela, B., Cavalletti, A., Gonella, M., and Tinti, S.: Applying and validating the PTVA-3 Model at the Aeolian Islands, Italy: assessment of the vulnerability of buildings to tsunamis, Nat. Hazards Earth Syst. Sci., 10, 1547-1562, doi:10.5194/nhess-10-1547-2010, 2010.

Dominey-Howes, D. and Papathoma, M.: Validating the Papathoma Tsunami Vulnerability Assessment Model (PTVAM) using field data from the 2004 Indian Ocean tsunami, Nat. Hazards, 53, 43$61,2007$.

Dominey-Howes, D., Dunbar, P., Varner, J., and Papathoma-Köhle, M.: Estimating Probable Maximum Loss from a Cascadia tsunami, Nat. Hazards, 53, 43-61, 2010. 
Eidsvig, U. M. K., Papathoma-Köhle, M., Du, J., T., G., and Vangelsten, B. V.: Quantification of model uncertainty in debris flow vulnerability assessment, Eng. Geol., 181, 15-26, 2014.

Fell, R. and Hartford, D.: Landslide Risk Management, in: Landslide Risk Assessment, edited by: Cruden, D. M. and Fell, R., Balkema, Rotterdam, 1997.

Fuchs, S.: Susceptibility versus resilience to mountain hazards in Austria - paradigms of vulnerability revisited, Nat. Hazards Earth Syst. Sci., 9, 337-352, doi:10.5194/nhess-9-337-2009, 2009.

Fuchs, S., Heiss, K., and Hübl, J.: Towards an empirical vulnerability function for use in debris flow risk assessment, Nat. Hazards Earth Syst. Sci., 7, 495-506, doi:10.5194/nhess-7-4952007, 2007.

Fuchs, S., Kuhlicke, C., and Meyer, V.: Vulnerability to natural hazards - the challenge of integration, Nat. Hazards, 58, 609-619, 2011.

Fuchs, S., Birkmann, J., and Glade, T.: Vulnerability assessment in natural hazard and risk analysis: current approaches and future challenges, Nat. Hazards, 64, 1969-1975, 2012.

Fuchs, S., Keiler, M., Sokratov, S. A., and Shnyparkov, A.: Spatiotemporal dynamics: the need for an innovative approach in mountain hazard risk management, Nat. Hazards, 68, 12171241, 2013.

Fuchs, S., Keiler, M., and Zischg, A.: A spatiotemporal multihazard exposure assessment based on property data, Nat. Hazards Earth Syst. Sci., 15, 2127-2142, doi:10.5194/nhess-152127-2015, 2015.

Gems, B., Mazzorana, B., Hofer, T., Sturm, M., Gabl, R., and Aufleger, M.: 3-D hydrodynamic modelling of flood impacts on a building and indoor flooding processes, Nat. Hazards Earth Syst. Sci., 16, 1351-1368, doi:10.5194/nhess-16-1351-2016, 2016.

Haigh, R.: Discussion paper: Developing a resilient built environment: post-disaster reconstruction as a window of opportunity, Kandy, 13-14 December 2010.

HAZUS: Multi-Hazard Loss Estimation Methodology Earthquake Model, HAZUS MH-MR2, User Manual, FEMA and NIBS, Washington, D.C., 2006.

Holub, M. and Fuchs, S.: Mitigating mountain hazards in Austria - legislation, risk transfer, and awareness building, Nat. Hazards Earth Syst. Sci., 9, 523-537, doi:10.5194/nhess-9-5232009, 2009.

Holub, M., Suda, J., and Fuchs, S.: Mountain hazards: reducing vulnerability by adapted building design, Environ. Earth Sci., 66, 1853-1870, 2012.

Kappes, M., Papathoma-Köhle, M., and Keiler, M.: Assessing physical vulnerability for multi-hazards using an indicator-based methodology, Appl. Geogr., 32, 577-590, 2012.

Karagiorgos, K., Thaler, T., Hübl, J., Maris, F., and Fuchs, F.: Multivulnerability analysis for flash flood risk management, Nat. Hazards, 82, S63-S87, 2016.

Kaswalder, C.: Schätzungsstudie zur Berechnung des Schadenspotentials bei Hochwasserereignissen durch die Rienz im Abschnitt Bruneck - St. Lorenzen, Autonome Provinz Bozen - Südtirol, Bozen, South Tyrol, 2009.

Keiler, M., Knight, J., and Harrison, S.: Climate change and geomorphological hazards in the eastern European Alps, Philos. T. Roy. Soc. A, 368, 2461-2479, 2010.
Leone, F., Aste, J.-P., and Velasquez, E.: Contribution des constats d' endommagement au developpement d' une methodologie d'evaluation de la vulnerabilite applique aux phenomenes de mouvements de terrain, Bulletin de l' Association de Geographes, Paris, 350-371, 1995.

Leone, F., Aste, J.-P., and Leroi, E.: L'evaluation de la vulnerabilite aux mouvements du terrain: Pour une meilleure quantification du risque, Revue de geographie Alpine, 84, 35-46, 1996.

Liu, X. and Lei, J.: A method for assessing regional debris flow risk: an application in Zhaotong of Yunnan province (SW China), Geomorphology, 52, 181-191, 2003.

Lo, W.-C., Tsao, T.-C., and Hsu, C.-H.: Building vulnerability to debris flows in Taiwan: a preliminary study, Nat. Hazards, 64, 2107-2128, 2012.

Martell: http://www.gemeinde.martell.bz.it/gemeindeamt/html/, last access: 13 July 2013.

Mazzorana, B., Comiti, F., Scherer, C., and Fuchs, S.: Developing consistent scenarios to assess flood hazards in mountain streams, J. Environ. Manage., 94, 112-124, 2012.

Mazzorana, B., Hübl, J., and Fuchs, S.: Improving risk assessment by defining consistent and reliable system scenarios, Nat. Hazards Earth Syst. Sci., 9, 145-159, doi:10.5194/nhess-9-1452009, 2009.

Mazzorana, B., Simoni, S., Scherer, C., Gems, B., Fuchs, S., and Keiler, M.: A physical approach on flood risk vulnerability of buildings, Hydrol. Earth Syst. Sci., 18, 3817-3836, doi:10.5194/hess-18-3817-2014, 2014.

Müller, A., Reiter, J., and Weiland, U.: Assessment of urban vulnerability towards floods using an indicator-based approach - a case study for Santiago de Chile, Nat. Hazards Earth Syst. Sci., 11, 2107-2123, doi:10.5194/nhess-11-2107-2011, 2011.

Papathoma, M. and Dominey-Howes, D.: Tsunami vulnerability assessment and its implications for coastal hazard analysis and disaster management planning, Gulf of Corinth, Greece, Nat. Hazards Earth Syst. Sci., 3, 733-747, doi:10.5194/nhess-3-7332003, 2003.

Papathoma, M., Dominey-Howes, D., Zong, Y., and Smith, D.: Assessing tsunami vulnerability, an example from Herakleio, Crete, Nat. Hazards Earth Syst. Sci., 3, 377-389, doi:10.5194/nhess-3377-2003, 2003.

Papathoma-Köhle, M. and Ciurean, R.: Integrating physical vulnerability models in a holistic framework- a tool for practicioners, Geophys. Res. Abstr., 16, EGU2014-3459, 2014.

Papathoma-Köhle, M., Neuhäuser, B., Ratzinger, K., Wenzel, H., and Dominey-Howes, D.: Elements at risk as a framework for assessing the vulnerability of communities to landslides, Nat. Hazards Earth Syst. Sci., 7, 765-779, doi:10.5194/nhess-7-7652007, 2007.

Papathoma-Köhle, M., Kappes, M., Keiler, M., and Glade, T.: Physical vulnerability assessment for alpine hazards:state of the art and future needs, Nat. Hazards, 58, 645-680, 2011.

Papathoma-Köhle, M., Totschnig, R., Keiler, M., and Glade, T.: Improvement of vulnerability curves using data from extreme events, Nat. Hazards, 64, 2083-2105, 2012.

Papathoma-Köhle, M., Zischg, A., Fuchs, S., Glade, T., and Keiler, M.: Loss estimation for landslides in mountain areas-an integrated toolbox for vulnerability assessment and damage documentation, Environ. Model. Softw., 63, 156-169, 2015. 
Pfitscher, A.: Wasserkatastrophen in Martelltal - Der 24./25. August 1987, Municipality Martell, Martell, 1996.

Quan Luna, B., Blahut, J., van Westen, C. J., Sterlacchini, S., van Asch, T. W. J., and Akbas, S. O.: The application of numerical debris flow modelling for the generation of physical vulnerability curves, Nat. Hazards Earth Syst. Sci., 11, 2047-2060, doi:10.5194/nhess-11-2047-2011, 2011.

Rheinberger, C. M., Romang, H. E., and Bründl, M.: Proportional loss functions for debris flow events, Nat. Hazards Earth Syst. Sci., 13, 2147-2156, doi:10.5194/nhess-13-2147-2013, 2013.

Romang, H.: Wirksamkeit und Kosten von WildbachSchutzmassnahmen, Verlag des Geographischen Instituts der Universität Bern, Bern, 2004.

Scheer, S., Gardi, A., Guillande, R., Eftichidis, G., Varela, V., and de Vanssay, B.: Handbook of Tsunami Evacuation Planning European Union, JRC, Ispra, Italy, 2011.

Silva, M. and Pereira, S.: Assessment of physical vulnerability and potential losses of buildings due to shallow slides, Nat. Hazards, 72, 1029-1050, 2014.

Sterlacchini, S., Frigerio, S., Giacomelli, P., and Brambilla, M.: Landslide risk analysis: a multi-disciplinary methodological approach, Nat. Hazards Earth Syst. Sci., 7, 657-675, doi:10.5194/nhess-7-657-2007, 2007.

Tarbotton, C., Dominey-Howes, D., Goff, J. R., Papathoma-Köhle, M., Dall'Osso, F., and Turner, I. L.: GIS-based techniques for assessing the vulnerability of buildings to tsunami: current approaches and future steps, in: Natural Hazards in the Asia-Pacific Region: recent advances and Emerging Concepts, edited by: Terry, J. P. and Goff, J., Geologicaol Society, London, 2012.

Tarbotton, C., Dall'Osso, F., Dominey-Howes, D., and Goff, J.: The use of empirical vulnerability functions to assess the response of buildings to tsunami impact: comparative review and summary of best practice, Earth-Sci. Rev., 142, 120-134, 2015.
Thaler, T. and Levin-Keitel, M.: Multi-level stakeholder engagement in flood risk management - a question of roles and power: Lessons from England, Environ. Sci. Policy, 55, 292-301, 2016.

Thaler, T., Priest, S., and Fuchs, S.: Evolving interregional cooperation in flood risk management: distances and types of pertnership approaches in Austria, Reg. Environ. Change, 16, 841853, 2016.

Totschnig, R. and Fuchs, S.: Mountain torrents: quantifying vulnerability and assessing uncertainties, Eng. Geol., 155, 31-44, 2013.

Totschnig, R., Sedlacek, W., and Fuchs, S.: A quantitative vulnerability function for fluvial sediment transport, Nat. Hazards, 58, 681-703, 2011.

UN: Hyogo Framework for Action 2005-2015: Building the Resilience of Nations and Communities to Disasters, Kyoto, Japan, 2007.

UNDRO: Disaster Prevention and mitigation-a compendium of current knowledge, UN, New York, 1984.

UNISDR: UNISDR Terminology on Disaster Risk Reduction, UN, Geneva, Switzerland, 2009.

Velotti, L., Trainor, J. E., Engel, K., Torres, M., and Myamoto, T.: Beyond vertical evacuation: research considerations for a comprehensive "vertical protection srategy", Int. J. Mass Emerg. Disast., 31, 60-77, 2013.

Zanchetta, G., Sulpizio, R., Pareschi, M. T., Leoni, F. M., and Santacroce, R.: Characteristics of May 5-6, 1998 volcaniclastic debris flows in the Sarno area (Campania, southern Italy): relationships to structural damage and hazard zonation, J. Volcanol. Geoth. Res., 133, 377-393, 2004.

Zhang, J., Guo, Z. X., Wang, D., and Qian, H.: The quantitative estimation of the vulnerability of brick and concrete wall impacted by an experimental boulder, Nat. Hazards Earth Syst. Sci., 16, 299-309, doi:10.5194/nhess-16-299-2016, 2016. 